$\mathcal{G S}_{\text {http://dx.doi.org/10.3765/sp.10.9 }}^{\text {Semantics \& Pragmatics Volume 10, Article 9, } 2017}$

This is an EARLY ACCESS version of

Schlenker, Philippe. 2017. Super monsters I: Attitude and Action Role Shift in sign language. Semantics and Pragmatics 10(9). http://dx.doi.org/10. 3765/sp.10.9.

This version will be replaced with the final typeset version in due course. Note that page numbers will change, so cite with caution. 
EARLY ACCESS

\title{
Super monsters I: Attitude and Action Role Shift in sign language*
}

\author{
Philippe Schlenker \\ Institut Jean-Nicod, CNRS \\ New York University
}

Submitted 2014-05-18 / First decision 2014-11-08 / Revision received 2015-03-05 / Second decision 2015-05-03 / Accepted 2015-06-28

\begin{abstract}
In sign language 'Role Shift', the signer can adopt another person's perspective to report a propositional attitude ('Attitude Role Shift') or an action ('Action Role Shift', often called 'Constructed Action'); this is overtly marked by various means, such as a rotation of the signer's body and/or eyegaze shift. This operation can be analyzed as an overt instantiation of the 'monstrous' mechanism of 'context shift' postulated for attitude reports in some spoken languages (Schlenker 2003, Anand \& Nevins 2004, Anand 2006, Quer 2005). For Attitude Role Shift, we argue that this analysis brings new light to the typology of context-shifting operations: while some sign languages make it possible to 'mix perspectives' under Role Shift (Quer 2005), we argue that ASL and LSF obey the constraint that indexicals should 'shift together' (Anand 2006). Still, in ASL and LSF, data from Attitude Role Shift alone cannot fully exclude an alternative analysis based on quotation without context shift. By contrast, Action Role Shift, which has no established counterpart in spoken language, is not amenable to a quotational analysis because it is used to describe actions that don't involve any speech- or thought-acts; in that respect, Role Shift is a 'super monster' that can shift the context outside of attitude reports. We develop a context-shifting analysis that applies both to Attitude and to Action Role Shift. (Important shortcomings of this analysis are discussed in Part II, which extends the theory with an 'iconic component' that addresses them.)
\end{abstract}

* ASL consultant for this article: Jonathan Lamberton. Special thanks to Jonathan Lamberton, who has provided exceptionally fine-grained data throughout this research; his contribution as a consultant has been considerable. He also provided and/or checked ASL transcriptions and translations.

LSF consultant for this article: Ludovic Ducasse. Special thanks also to Ludovic Ducasse, who has provided very detailed judgments on complex sentences throughout this research.

Thanks to Kathryn Davidson and to audiences at NYU for helpful suggestions. Special thanks to three referees for Semantics \& Pragmatics, to Sandro Zucchi, and to David Beaver for extremely detailed and helpful comments. The references were prepared by Lucie Ravaux, who also checked the computation of average judgments given with example sentences. The research leading to these results received funding from the European Research Council under the European Union's Seventh Framework Programme (FP/2007-2013) / ERC Grant Agreement N³24115-FRONTSEM (PI: Schlenker). Research was conducted at Institut d'Etudes Cognitives (ENS), which is supported by grants ANR-10-IDEX-0001-02 PSL* and ANR-10-LABX-0087 IEC. The research reported in this piece also contributes to the COST Action IS1006. 
Philippe Schlenker

Keywords: sign language, role shift, context shift, monsters, indexicals, attitude reports

\section{Introduction}

\subsection{Role shift}

Two strands of research on context-dependency have come together in recent years. In the semantics of spoken languages, considerable attention has been devoted to the phenomenon of context shift. The chief motivation lay in the behavior of indexicals. While these were traditionally thought to depend rigidly on the context of the actual speech act, it turned out that there are languages and constructions in which this is not so: some attitude operators appear to be able to 'shift the context of evaluation' of some or all indexicals (e.g. Schlenker 1999, 2003, 2011, Anand $\&$ Nevins 2004, Anand 2006). In research on sign languages, there has been a long-standing interest in Role Shift, an overt operation (often marked by body shift and/or eyegaze shift) by which the signer signals that he adopts the perspective of another individual (e.g. Padden 1986, Lillo-Martin 1995, Sandler \& Lillo-Martin 2006). Role Shift comes in two varieties: it may be used to report an individual's speech or thought — henceforth 'Attitude Role Shift'. Or it may be used to report in a particularly vivid way an individual's actions (henceforth 'Action Role Shift'; a more traditional term in sign language research is 'Constructed Action') ${ }^{1}$. Attitude Role Shift has sometimes been analyzed as an overt instance of context shift because some or all indexicals that appear in that environment acquire a shifted interpretation (Quer 2005). On the basis of data from American and French Sign Language (ASL and LSF), we argue that this analysis brings new light to the typology of context-shifting operations: while some sign languages make it possible to 'mix perspectives' under Role Shift (Quer 2005, Herrmann \& Steinbach 2012), we suggest that ASL and LSF obey Anand and Nevins's constraint that indexicals should 'shift together'. Still, in ASL and LSF, data from Attitude Role Shift alone cannot fully exclude an alternative analysis based on quotation without context shift (especially one in terms of mixed quotation, as in Maier to appear). By contrast, Action Role Shift, which has no established counterpart in spoken language, is not amenable to a quotational analysis because it is used to describe actions that don't involve any speech- or thought-acts; in that respect, the context-shifting operations we find in sign language are 'super monsters' that can shift the context outside of attitude reports. We develop a contextshifting analysis that applies both to Attitude and to Action Role Shift. (Important

1 While the term 'Action Role Shift' is new, the observation that Role Shift can be used beyond attitude reports is not; see for instance the survey in Sandler \& Lillo-Martin 2006, where it is noted that Role Shift "can be described as quoting the thoughts of another or simply representing a scene from the point of view of another" (p. 380). 
Super monsters I

shortcomings of this analysis are discussed in Part II, which extends the theory with an 'iconic component' that addresses them. In Part II, we will thus see that Role Shift is a 'super monster' not just in that it can shift the context outside of attitude reports, but also in that it has an iconic and thus hyperintensional component.)

\subsection{Elicitation methods and glossing conventions}

\subsubsection{Elicitation methods}

In ASL and LSF alike, our elicitation method involved three steps.

(i) First, we elicited sentences of interest with a Deaf native signer (Deaf child of Deaf, signing parents). Our emphasis was on the construction of controlled paradigms, usually of two to four sentences. All examples were videotaped.

(ii) Second, we showed the resulting videos to the same signer, asking him to rate the sentences on a 7 -point scale (with $7=$ best and $1=$ worst), and often to answer inferential questions. All judgments were entered in a computer and then signed and explained in further detail on a video.

(iii) Step (ii) was usually repeated with the same method several times, usually on separate days, in order to assess the stability of our consultant's judgments.

Unless otherwise noted, ASL data are based on repeated judgments by a single Deaf signer (Deaf child of Deaf, signing parents), and similarly for LSF (the consultant is also the Deaf child of Deaf, signing parents). All the ratings for sentences that didn't appear in earlier publications are found in Appendix IV (sometimes in abbreviated form when it comes to inferential questions). Averages of the various trials for the relevant consultant are provided in front of each original sentence in the main text, with numerical scores in lieu of the customary symbols *, ??, ? used in generative grammar. Unless stated otherwise, acceptability is assessed in the context given, without specifying which reading is intended; inferential questions assess meaning separately from acceptability. Sentences are followed by the language they are from, with the reference of the video in which they were signed (thus $A S L, 14,91$ will follow example (7) because this an ASL sentence recorded in video 14, 91).

One important note is in order about translations. Part of the debate about Role Shift is whether it involves some variety of quotation. While we will argue that a quotational analysis has some flaws, we will opportunistically use translations with quotations when this makes it easier to understand the behavior of some elements, such as shifted indexicals (when a translation with quotation is too convoluted - as in the case of wh-extraction out of role-shifted clauses - we will use translations with indirect discourse instead). No theoretical decision should be read into these 
translations. ${ }^{2}$ Let us add that ASL verbs are often underspecified between present, past or future - something which is hard to preserve in translations; glosses should be consulted when this matters.

\subsubsection{Glossing conventions}

In the following, sign language sentences are glossed in capital letters. Non-manual markings are omitted, except for Role Shift, which in all cases involves at least body shift and eyegaze shift (and possibly other non-manuals as well); it is notated by adding $R S_{a} \quad$ above the role-shifted elements, where a is the perspectival origin of the Role Shift. Subscripts correspond to the establishment of locations ('loci') in signing space. Letters are assigned from right to left from the signer's perspective. Pronouns, glossed as $I X$ (for 'index'), can point back towards previously established loci. In such cases, the locus is suffixed to the pronoun, so that $I X-a$ is a pronoun that points towards (or 'indexes') locus $a$; the numbers 1 and 2 correspond to the position of the signer and addressee respectively. Importantly, indexes can also be used to establish a locus, hence the appearance of $I X$ in positions that are not pronominal. $I X$-arc- $a$ refers to a plural index, realized with an arc-shaped pointing sign indexing locus a; -rep is used when a sign is repeated. An expression which is signed in locus $a$ is transcribed with $a$ as a subscript; this is in particular the case of classifiers, e.g. $C L_{a}$ stands for a classifier signed in locus $a$. $C L$ is also suffixed at the end of the glosses for classifier verbs; thus 1-WALK-WITH-ENERGY(CL-ONE) indicates that this ASL verb involves the index finger classifier, and $S H O W-C L$ refers to an LSF classifier verb.

\section{Attitude Role Shift I: Catalan and German Sign Language (LSC and DGS)}

As summarized in Quer to appear, Role Shift across sign languages is morphosyntactically characterized by non-manual markers such as the following: (i) 'temporary interruption of eye contact with the actual interlocutor and direction change of eye gaze towards the reported interlocutor'; (ii) 'slight shift of the upper body in the direction of the locus associated with the author of the reported utterance'; (iii) 'change in head position'; (iv) 'facial expression associated to the reported agent.' What semantics should be associated to these formal properties? In this section, we discuss the prospects of a theory in which Role Shift is an overt realization of context shift. ${ }^{3}$

2 It must be added, however, that in Part II we will see that Attitude Role Shift genuinely has a quotational component.

3 Because we are not certain that all four properties listed by Quer target the very same phenomenon, we will concentrate in our own data on instances of Role Shift which at least include body shift and 
Super monsters I

Following much of the literature, we start with Attitude Role Shift, and argue (following Quer 2005) that it can be analyzed as an overt instantiation of context shift. The latter operation was postulated for a variety of constructions across languages in which a clause under an attitude verb could be shown not to involve standard direct quotation, and yet to allow some indexicals to be evaluated with respect to the context of the reported speech act (Schlenker 1999, 2003, 2011; Anand \& Nevins 2004, Anand 2006). Quer 2005 argued that in Catalan Sign Language (LSC) Attitude Role Shift is in fact an overt realization of context shift. For such an argument to be cogent, however, two conditions are needed. (i) First, it must be shown that at least some indexicals can be evaluated with respect to a shifted context under Role Shift. (ii) Second, an alternative analysis must be excluded, one in which the role-shifted clause is simply quoted - for quoted clauses are arguably mentioned rather than used, which obviates the need to evaluate their content relative to a shifted context. (At this point, we assume that quotation must target an entire clause, and we come back in Section 5 to the possibility of a theory with 'partial quotation', as argued in Maier, to appear.) Quer's data (2005, to appear) satisfy conditions (i) and (ii) in a particularly straightforward fashion. First, some indexicals in Attitude Role Shift in LSC have a shifted interpretation, i.e. are intuitively evaluated with respect to the context of the reported speech act. Second, it is not the case that the entire role-shifted clause is quoted. This is because other indexicals can be evaluated with respect to the context of the actual speech act. This pattern is illustrated in (1), where the first person pronoun IX-1 is evaluated with respect to the reported context (and

eyegaze shift. But this does not entail that body shift is the most common way to realize role shift as standardly construed; Quer (to appear) argues on the basis of Catalan sign language (LSC) and German sign language (DGS) data that this is in fact a relatively infrequent strategy. Thus he writes: "In a small corpus study, Herrmann \& Steinbach $(2009,2010)$ established for German Sign Language (DGS) that the only required articulation to mark role shift is eye gaze break, which seems sufficient to identify a discourse segment as role shift from a formal point of view. This is confirmed by signers' intuitions for LSC. The fact is that, even though marking by the whole array of non-manuals can be very obvious, sometimes it is extremely subtle, especially when only one marker is found." Herrmann \& Steinbach 2012 write about their German Sign Language data: "Out of 171 role shifts found in the data, $168(98 \%)$ are marked by facial expressions, $147(86 \%)$ show an eye gaze change towards the addressee of the reported situation. In $131(77 \%)$ of the cases, we observe head movement towards the addressee of the reported utterance. Surprisingly, only $82(48 \%)$ of the role shifts involve a kind of body lean." They propose an implicational hierarchy as in (i), where Role Shift is taken to involve all the elements in (ia), or just those of in (ib), or the single element in (ic).

(i) a. eye gaze + head position + body lean

b. eye gaze + head position

c. eye gaze 
thus refers to Joan [=JOAN]), while $H E R E$ is evaluated with respect to the actual context.

(1) $\frac{\mathrm{t}}{\text { IX-a MADRID } \text { MOMENT JOAN }_{\mathrm{i}}} \frac{\mathrm{RS}_{\mathrm{i}}}{\text { THINK IX-1 }_{\mathrm{i}} \text { STUDY FINISH HERE }_{\mathrm{b}}}$ 'When he was in Madrid, Joan thought he would finish his study here (in Barcelona).'

(LSC, Quer 2005, to appear)

As emphasized by Quer (to appear), it is also possible to understand HERE as being shifted, as in (2); but the 'mixing of perspectives' found in (1) is particularly important in order to argue that there is context shift rather than standard quotation.

(2) $\frac{\mathrm{t}}{\text { IX-a MADRID JOAN }} \mathrm{RS}_{\mathrm{i}} \mathrm{THINK}_{\mathrm{TX}-1_{\mathrm{i}} \text { STUDY FINISH HERE MADRID }}$

'When he was in Madrid, Joan thought he would finish his study there in Madrid.'

(LSC, Quer to appear)

In the end, (Quer to appear) suggests on the basis of syntactic evidence that Attitude Role Shift in Catalan Sign Language can in some contexts involve bona fide quotation, but that in other contexts it involves indirect discourse with some shifted indexicals. For present purposes, we are only concerned with cases that can be shown not to involve standard quotation. ${ }^{4}$

The same logic applies to data unearthed in German Sign Language (DGS) by Herrmann \& Steinbach 2012. As they write, "temporal and local indexicals such as TOMORROW (...) need not be interpreted in the shifted context but can also be interpreted in the actual context", as is the case in (3) (we have kept their notation, whereby $3 a<\quad>3 b$ indicates that the role-shifted clause is signed from the perspective of locus a and towards locus $b$, where both are third person loci).

(3) YESTERDAY PETER IX 3a $_{\text {a }}$ SAY TOMORROW IX ${ }_{1}$ ARRIVE 'Yesterday Peter said that he will arrive tomorrow.' (DGS, Herrmann \& Steinbach 2012)

In this case, $I X-1$ is evaluated with respect to the reported context and receives a shifted interpretation, whereas TOMORROW can be interpreted with respect to the

4 Quer, to appear writes that "direct quotes in LSC can be preposed (topicalized)" in sentences that include a marker of direct discourse made of the LSC words SENTENCE SAME. By contrast, "ungrammaticality results if we try to do the same with a role shift segment which is interpreted as indirect discourse". 
Super monsters I

actual context. This 'mixing of perspectives' shows that we are not dealing with standard quotation..$^{5}$

\section{Attitude Role Shift II: American Sign Language (ASL)}

In our ASL data, Quer's argument from 'mixing of perspectives' isn't applicable, because we haven't found any instances of Role Shift in which indexicals fail to be evaluated with respect to the shifted context (the consequences of this observation for the typology of context-shifting operations are discussed in Section 6.1). Still, standard tests can in principle be used to distinguish indirect discourse from standard (i.e. full clause) quotation; we return below to the possibility that our cases involve partial quotation. As we will see, they yield a rather complex picture, parts of which are compatible with a quotational analysis. The analysis of Action Role Shift will in the end be rather crucial to argue for a context-shifting theory.

\subsection{Extraction tests and NPI tests ${ }^{6}$}

In English, quotations are typically thought to involve clauses that are not integrated to the rest of their environment because no grammatical dependencies can 'cross quotation marks', as is illustrated in (4) and (5).

(4) a. What did John say he understands _?

b. *What did John say 'I understand _'?

c. John said: 'I understand chemistry'.

(5) a. John didn't say he understands any chemistry.

b. * John didn't say 'I understand any chemistry'.

c. John didn't say: 'I understand chemistry'.

In (4a), a dependency exists between the 'gap' after the embedded verb, which represents a missing object, and the interrogative word at the beginning of the sentence; but this dependency is impossible in (4b), which involves a quotation (there is an irrelevant reading if the quotation marks are dropped, on which $I$ refers to the actual speaker rather than to John; this reading could equally be obtained with

5 Herrmann \& Steinbach 2012 note that "similar examples can also be found in reported speech in spoken languages like Slave (Northern Athapaskan, a language spoken in the Northwest of Canada), where first and second person indexicals in the complement clauses of verbs like 'to say' need not be interpreted in the context of the actual utterance but can be bound by the context of the reported utterance (for discussions and examples cf. Herrmann \& Steinbach 2007; Quer 2005, 2011; Rice 1986; Schlenker 2003; Zucchi 2004)."

6 This section follows a similar development in Schlenker 2011. 
the sentence What did John say that I understand?). In (5a), there is a dependency between the negative polarity item any and the matrix negation (as is shown by the fact that the sentence becomes odd when the matrix negation is dropped: *John claimed that he understands any chemistry). In (5b), this dependency is made impossible by the quotation marks. One way to account for these facts is by positing that quoted material is mentioned/shown rather than used, and that for this reason it fails to be grammatically integrated to its broader environment.

\subsection{Extraction tests in ASL: main data}

Focusing for the moment on the extraction tests, it would appear that some ASL consultants treat role-shifted clauses as being integrated to their syntactic environment. In (6), one of our early examples pertaining to this topic, we provide two consultants' judgments on sentences involving both $w h$-extraction and embedded indexicals $;^{7}$ the extraction strategy used involves a clause-initial $w h$-word, doubled clause-finally by the same word (there are other extraction strategies, but this one is clear and well-accepted). As is standard (though not obligatory) in ASL, the extraction strategy involves a reduplicated $w h$-word, which appears both in sentence-initial and in sentence-final position. The result is still acceptable - and HERE is evaluated with respect to the context of the reported speech act (the same applies to $I X-1$, though this was not the main point of this initial test; we come back to this point in Section 6.3).

(6) Context: the speaker is in NYC.

$7^{8}$ IN LA WHO IX-a [JOHN $\left.{ }_{\mathrm{a}}\right]$ SAY IX-1 WILL MEET HERE WHO

Informant JL (on a video on which he signed the sentence with $\mathrm{JOHN}_{a}$ [ASL, 6, 316]): 7, HERE = LA

Informant 2 (on a video on which he signed the sentence without $J O H N_{a}$, and with $I X$ - $a$ replacing IN [ASL, 6, 293]): 7, HERE = preferably LA [6, 294-295] 'In LA, who did John/he say he would meet there [in LA]?'

$7 \mathrm{JL}$ is our main ASL consultant. The other consultant is deaf and started using ASL from birth with two older siblings who had already acquired it from Deaf school by the time he was born. 
These examples have one potential drawback, however: MEET is an 'agreement verb', i.e. a type of verb that was shown in Lillo-Martin 1991 to license null pronominal arguments. ${ }^{9}$ Thus one could seek to re-analyze these data as involving a direct discourse with a null pronoun, yielding a result somewhat similar to: In LA, who is the person about whom John said: 'I will meet him here'?'10

To control for this possibility, we obtained repeated judgments from our main consultant on (7)-(8), which involve wh-extraction out of the construction LIVE WITH, which is a non-agreeing construction. The result is about as good with Role Shift as without it. Furthermore, it can be checked that without an overt complement argument, LIVE WITH is deviant, as in (9b); and it remains degraded even when there is a salient (but unexpressed) antecedent, as in (10c). This makes it very unlikely that (7) could involve standard direct discourse.

(7) Context: The speaker is in NYC; the listener was recently in LA with John. BEFORE IX-a JOHN IN LA [= while in LA], RS 6.7 WHO IX-a SAY IX-1 WILL LIVE WITH HERE WHO 'While John was in LA, who did he say he would live with there?' (ASL, 14, 91)

(8) Context: The speaker is in NYC; the listener was recently in LA with John. BEFORE IX-a JOHN IN LA [= while in LA], 7 WHO IX-a SAY IX-a WILL LIVE WITH THERE WHO 'While John was in LA, who did he say he would live with there?' (ASL, 14, 93)

8 As noted, in these old data, we had judgments from two consultants. Informant 2 gave (i) an acceptability rating for the sentence $(=7)$, and (ii) a separate rating for different possible interpretations: $\mathrm{HERE}=\mathrm{LA}$ with a rating of 5/7; HERE $=\mathrm{NYC}$ with a rating of 2.5/7. Informant JL gave (i) an acceptability rating for the sentence $(=7)$, and (ii) a yes/no answer concerning possible interpretations of HERE (with 'yes' for HERE = LA and 'no' for HERE = NYC). The score 7 that appears before the sentence is the average of the two consultants' scores in the acceptability stage (without assessment of the possible readings).

9 We do not include loci in the gloss of MEET in (6) because it was signed in the 'neutral form' appropriate under Role Shift.

10 Thanks to Kathryn Davidson for mentioning this possibility. 
Philippe Schlenker

(9) a. $5^{11}$ IX-1 WILL MEET HERE.

b. 2 IX-1 WILL LIVE WITH HERE.

(ASL, 14, 95)

(10) a. 6 IX-1 HAVE MEETING WITH BILL . IX-1 WILL MEET $^{12}$ HERE. $^{-}$

b. 7 IX-1 HAVE MEETING WITH BILL ${ }_{a}$. IX-1 WILL MEET IX-a HERE.

c. 3 IX-1 HAVE MEETING WITH BILL . IX-1 WILL LIVE WITH HERE.

d. 7 IX-1 HAVE MEETING WITH BILL . IX-1 WILL LIVE WITH IX-a HERE.

(ASL, 17, 96)

\subsection{Extraction tests in ASL: further controls}

One might want to perform further controls to alleviate potential worries. First, can we show that $w h$-extraction is not syntactically unconstrained? The paradigm in (11) includes examples in which the role-shifted clause could be the argument of the main verb (= (11a) and (11c)), and cases in which it couldn't be because the object position is filled by SOMETHING IMPORTANT $(=(11 \mathrm{~b}))$. When $w h$-extraction is applied, as in (11), it appears to be blocked if the object argument of $S A Y$ is already filled. ${ }^{13}$ The contrast between (12) and $(12 \mathrm{a}, 12 \mathrm{c})$ suggests that the constraint is structural: extraction out of the propositional object of the verb is permissible in $(12 \mathrm{a}, 12 \mathrm{c})$ whereas extraction out of a non-integrated clause is degraded in (12b). Unsurprisingly, inferential questions show that in all cases $I X$ - $a$ refers to John while HERE refers to LA. Still, these data must be interpreted with caution, since the contrasts are a bit more subtle than one might expect.

11 As shown in Appendix IV, in 1 our of 3 trials our consultant gave two possible ratings depending on whether an appropriate context was included. We computed the average using his rating without a context, since we tested independently how an appropriate context could ameliorate the sentence.

12 In this paradigm, a non-agreeing form of MEET was used.

13 We also have a test in which the object position of $S A Y$ was filled with WHAT instead of being filled with SOMETHING IMPORTANT. The resulting sentences with $w h$-extraction might be a bit better than those with SOMETHING IMPORTANT, but since the syntactic analysis of the question-answer construction in ASL is not uncontroversial (Caponigro \& Davidson 2011), we leave it out of the present study. 
Super monsters I

(11) Context: The speaker is in NYC; the listener was recently in LA with John, and the speaker saw videos of the trip...

WHILE THE-TWO-a,b IN LA,

'While the two of them [= including John $]^{14}$ were in LA,

RS

a. 7 IX-a JOHN SAY: IX-1 WILL LIVE WITH MARY HERE.

John said: 'I will live with Mary here."

RS

b. 7 IX-a JOHN SAY SOMETHING IMPORTANT: IX-1 WILL LIVE WITH MARY HERE.

John said something important: 'I will live with Mary here."

c. 7 IX-a JOHN SAY REPEATEDLY: IX-1 WILL LIVE WITH MARY HERE. John said repeatedly: 'I will live with Mary here."

(ASL, 19, 25)

(12) Context: The speaker is in NYC; the listener was recently in LA with John, and the speaker saw videos of the trip...

WHILE THE-TWO-a,b IN LA,

'While the two of them [= including John] were in LA,

a. 7 WHO IX-a JOHN SAY IX-1 WILL LIVE WITH HERE WHO?

who did John say he would live with there?'

b. 4 WHO IX-a JOHN SAY SOMETHING IMPORTANT IX-1 WILL LIVE WITH HERE WHO?

c. 6 WHO IX-a JOHN SAY REPEATEDLY $\frac{\text { RS }}{\text { IX-1 WILL LIVE WITH HERE }}$ WHO?

who did John repeatedly say that he would live with there?'

(ASL, 19, 27)

Importantly, these data do not suffice to show that (12b) is degraded by comparison with (11b) because (12b) is quotational. For the same contrast can be replicated with non-quotational third person statements, as seen in (13) and (14). The latter do not involve quotation, but in (14) the clause from which wh-extraction is attempted fails to be integrated with the attitude verb, whose object position is already filled. By

14 We had intended the sentence to mean 'While John and you were in LA...', but upon watching the video our consultant noted that the second person locus does not appear to be indexed here. The same remark also applies to (12), (13) and (14). 
parity of reasoning, the lack of syntactic integration explains why (12b) is degraded, while (12a) is not.

(13) Context: The speaker is in NYC; the listener was recently in LA with John, and the speaker saw videos of the trip...

6.7 WHILE THE-TWO-a,b IN LA, IX-a JOHN SAY SOMETHING IMPORTANT IX-a WILL LIVE WITH MARY THERE.

'While the two of them [= including John] were in LA, John said something important — namely that he would live with Mary there.' (ASL, 19, 31)

(14) Context: The speaker is in NYC; the listener was recently in LA with John, and the speaker saw videos of the trip...

4.7 WHILE THE-TWO-a,b IN LA, WHO IX-a JOHN SAY SOMETHING IMPORTANT IX-a WILL LIVE WITH THERE WHO? (ASL, 19, 32)

In sum:

- (12b) and (14) show that long wh-extraction is not unconstrained, and fails when the movement originates in a clause that is not syntactically integrated with the attitude verb (because its object position is filled by something else).

- This suggests that in the 'good' cases of $w h$-extraction in (12a) and (12c) the role-shifted clause is syntactically integrated with the attitude verb. ${ }^{15}$

- These results per se do not suffice to exclude the possibility that wh-extraction is possible out of quotations. Further considerations (motivated by other languages, or by theory-internal arguments) would be needed to establish this point.

\subsection{De Se readings}

While $I X-1$ and HERE are usually taken to be indexical rather than anaphoric expressions, it is worth checking that the readings we obtained are those expected of

15 An anonymous reviewer suggests that other tests of indirect discourse could be used, notably (i) variable binding, and (ii) the De Re/De Dicto distinction. We leave these for future research, but note that each raises difficulties. (i) A sentence of the form WHO IX-2 SAY [RS IX-a <predicate> ] $(W H O)$., with a role-shifted embedded clause (and possibly with $w h$-reduplication), could be analyzed as an instance of variable binding; but it could also be interpreted as: Who is the person $x$ such that you said (about $x$ ): 'He <predicate>', with a mentioned deictic pronoun $I X$-a (possibly even re-using a locus $a$ introduced by the $w h$-expression). (ii) It is not entirely clear what is predicted about the De $\mathrm{Re} / \mathrm{De}$ Dicto distinction for languages in which Shift Together is obligatory; one might expect that the covert world argument of nominals behaves like an indexical and is thus obligatorily shifted as soon as other indexicals are — which would obligatorily yield De Dicto readings. 
Super monsters I

shifted indexicals. ${ }^{16}$ Given standard treatments (e.g. Schlenker 2003, 2011; Anand 2006), we expect a shifted indexical under an attitude operator to yield a 'De Se reading'. Briefly, a pronoun in indirect discourse is read 'De Se' when it reports the use of an indexical expression such as $I$ by the attitude holder. For example, 'PRO', the unpronounced subject of an infinitive, is always understood to report a first person (or in some cases a second person) thought when it is immediately embedded under an attitude verb (Morgan 1970, Chierchia 1987). This is illustrated by the following scenario, in which $P R O$ is inappropriate to report a third-person thought - by contrast with he, which is acceptable whether the thought to be reported was first- or third-personal.

(15) John is so drunk that he has forgotten that he is a candidate in the election. He watches someone on TV and finds that this person is a terrific candidate, and thinks: 'This guy should be elected'. Unbeknownst to John, the candidate he is watching on TV is John himself.

a. True: John hopes that he will be elected

b. False: John hopes PRO to be elected (Schlenker 2003) (by contrast, (b) is ok in a scenario in which the thought was: 'I should be elected')

Since shifted indexicals are supposed to be evaluated with respect to (what the agent takes to be) the context of the embedded clause, it stands to reason that they should be read De Se. This is indeed what we find in our ASL data (though our consultant initially revised his judgments, as shown in the raw data in Appendix IV). We asked our consultant to assess (separately) the acceptability and the truth of the sentences in (16a) (no Role Shift) and (16b) (Role Shift) in a De Se scenario (= (17)) and in a non-De Se scenario (= (18)). Both sentences were acceptable and true in the De Se scenario, but in the non-De Se scenario the report with Role Shift was dispreferred; this is expected if the shifted first person pronoun $I X-I$ only has a De Se reading.

16 There are two reasons to perform rigorous De Se tests with Role Shift.

- First, recent work by Hazel Pearson (Pearson 2012) suggests that in some cases expressions that have the distribution of obligatorily shifted indexicals (namely Ewe logophoric pronouns) may still fail to be unambiguously De Se.

- Second, the existence of Action Role Shift, which does not involve any propositional attitude and hence any De Se reading, suggests that one should be particularly cautious when investigating shifted indexicals in sign language (it could be that they are shifted by virtue of an extensional rather than an intensional shifting operation, which might affect the results of De Se tests). 
(16) a. IX-a JOHN THINK IX-a SIGN GOOD.

'John thinks that he signs well.'

b. IX-a JOHN THINK IX-1SIGN GOOD. 'John thinks: 'I sign well."

(ASL, 19, 133)

(17) Scenario A

We showed John lots of videos of people's hands signing — including videos of John signing. When we show him the video of his hands, John recognizes himself, and says: 'I sign well'

a. Judgments on (16a): 7, true

b. Judgments on (16b): 7 , true

(18) Scenario B

We showed John lots of videos of people's hands signing — including videos of John signing. When we show him the video of his hands, John doesn't recognize himself, and says: 'He signs well'

a. Judgments on (16a): 6, true [but see Appendix IV]

b. Judgments on (16b): 2, false [but see Appendix IV]

Unsurprisingly given current theories, the same generalizations can be obtained in examples that involve bound readings, as is shown in Appendix I.

\section{Attitude Role Shift III: French Sign Language (LSF)}

We turn to a briefer discussion of the properties of Attitude Role Shift in LSF.

\subsection{Shifting of all indexicals}

The first observation to be made is that under Attitude Role Shift all the indexicals we have tested appear to be obligatorily shifted. Thus while there is some amount of uncertainty about the point of evaluation of indexicals in standard indirect discourse, as in (19) (hence our question marks in the translations), there is no such uncertainty under Attitude Role Shift: both the first person pronoun and the time indexicals are obligatorily shifted in (20). 
Super monsters I

(19) Context: In 2010, I met Jean in LA. At the time, he often changed jobs and home bases.

DATE 2010 PLACE LA JEAN SAY

'In 2010, in LA, Jean said that

a. 7 YEAR NOW IX-a WORK PARIS.

this year [in 2013?] he would work in Paris.'

b. 7 YEAR-LAST IX-a WORK PARIS. last year [in 2012?] he would work (or had worked?) in Paris.'

c. 7 YEAR-NEXT IX-a WORK PARIS. next year [in 2014?] he would work in Paris.' $(\mathrm{LSF}, 32,70)^{17}$

(20) Context: In 2010, I met Jean in LA. At the time, he often changed jobs and home bases.

DATE 2010 PLACE LA JEAN SAY

'In 2010, in LA, Jean said:
$\frac{\mathrm{RS}_{\mathrm{a}}}{\mathrm{IX}-1}$
a. 7 IX-1 YEAR NOW WORK PARIS.
'This year I work in Paris.'
$\mathrm{RS}_{\mathrm{a}}$
b. $7 \overline{\text { YEAR-LAST IX-1 WORK PARIS. }}$
'Last year I worked in Paris."
$\mathrm{RS}_{\mathrm{a}}$
c. 7 YEAR-NEXT IX-1 WORK PARIS.
'Next year I will work in Paris."
(LSF, 32, 72)

The same generalization can be obtained on the basis of the locative indexical HERE, which is obligatorily shifted under Attitude Role Shift, as shown in (21).

(21) Context: In 2010, I met Jean in LA. At the time, he often changed jobs and home bases.

DATE 2010 PLACE LA JEAN SAY

'In 2010 in LA Jean said

\section{a. 7 DATE 2014 IX-a WORK HERE. \\ that in 2014 he would work here [= in Paris].'}

17 As shown in Appendix IV, in one of our three trials, the consultant mentioned that these sentences were ambiguous, with the temporal expressions evaluated with respect to the time of utterance or with respect to the time of Jean's speech act; in the other two trials, evaluation was with respect to the time of utterance. 
b. $7 \frac{\mathrm{RS}_{\mathrm{a}}}{\mathrm{DATE}} 2014$ IX-1 WORK HERE.

:'In 2014 I will work here."

(LSF, 32, 74)

We have similar data pertaining to the obligatory shifting of NOW, TOMORROW, THE-DAY-BEFORE-YESTERDAY, and (less clearly) YESTERDAY under Attitude Role Shift. (In our data, these adverbials co-occur with $I X-1$, which also obligatorily shifts). ${ }^{18}$

Since all indexicals obligatorily shift under Attitude Role Shift, based on the foregoing data we cannot rule out the possibility that LSF Attitude Role Shift involves the kind of quotation which is found in English. In our ASL data, we could rule out this possibility because wh-extraction was permissible out of Attitude Role Shift. As we will now see, this is not the case in LSF. (It will thus be for theoryinternal reasons, related to the existence of Action Role Shift, that we will posit that role-shifted clauses in general don't just involve quotation ${ }^{19}$ ).

\subsection{Failure of the extraction test}

In LSF, our main consultant dislikes extraction out of role-shifted clauses. The baseline is in (22): we used two patterns of $w h$-extraction out of standard indirect discourse, one with a single $W H O$, which appears in the post-verbal position, and another one with a doubled $w h$-word, with $W H O$ appearing both at the beginning of the embedded clause and in the post-verbal position. To ensure that we obtained a matrix $w h$-question, we elicited the sentence by way of a transformation task, in which we showed the signer the transcription in (22a), and asked him to form the question corresponding to the underlined word - which led to the two patterns in (22b) and (22c). We checked by way of inferential questions that appear in Appendix IV that the latter two were indeed interpreted as matrix questions.
a. 7 PIERRE SAY IX-a LIKE MARIE. 'Pierre says he likes Marie.'
b. 7 PIERRE SAY IX-a LIKE WHO? $\Rightarrow$ the speaker wants to know who Pierre likes 'Who did/does Pierre say he likes?'
c. 7 PIERRE SAY WHO IX-a LIKE WHO? $\Rightarrow$ the speaker wants to know who Pierre likes

18 Some relevant videos are 32, 44; 32, 5 (and 32, 8); 32, 46; and 32, 44 respectively. Of course one can never exclude the possibility that other indexicals might display a different behavior.

19 In Part II of the present study, we will show that Attitude Role Shift in ASL and LSF always has a quotational component. 
Super monsters I

'Who did/does Pierre say he likes?'

(LSF, 34, 146)

A similar transformation task with a role-shifted clause failed: the consultant just said that no corresponding question could be asked. We then asked the consultant to sign the role-shifted clause with $W H O$ added outside of Role Shift, in the same positions as in the 'good' sentences in (22b) and (22c). The result was sharply deviant, as seen in (23b) and (23c).
a. 7 PIERRE SAY IX-1 LIKE MARIE
'Pierre says/said that he likes Marie.'
b. 1 PIERRE SAY IX-1 LIKE WHO?
c. 1 PIERRE SAY WHO IX-1 LIKE WHO? (LSF, 34, 149)

We asked our consultant to sign the sentences again, but this time with the wh-words under Role Shift. The result was acceptable but the meaning changed: we obtained embedded (or quoted) rather than matrix questions.
$\mathrm{RS}_{\mathrm{a}}$
a. 7 PIERRE SAY IX-1 LIKE MARIE.
'Pierre says/said: 'I like Marie."
b. 7 PIERRE SAY IX-1 LIKE WHO?
$\Rightarrow$ Pierre wants to know who he likes
'Pierre says/said: 'Who do I like?"
c. 7 PIERRE SAY $\frac{\mathrm{RS}_{\mathrm{a}}}{\mathrm{WHO} \text { IX-1 LIKE WHO? }}$
$\Rightarrow$ Pierre wants to know who he likes
'Pierre says/said: 'Who do I like?'
(LSF, 34, 150)

Finally, we checked whether the results were any different if the interrogative word appeared in matrix position; without a copy of the interrogative word in the embedded position the result was degraded even without Role Shift. But either way, interrogative extraction out of a role-shifted clause appeared to be prohibited, as shown by the following contrasts. 
a. 7 WHO PIERRE SAY IX-a LIKE WHO?

'Who did/does Pierre say he likes?'

b. 5.5 WHO PIERRE SAY IX-a LIKE?

'Who did/does Pierre say he likes?'

(LSF, 35, 4 b, c)
RS
a. 1 WHO PIERRE SAY IX-1 LIKE WHO?
RS
b. $2.5^{20}$ WHO PIERRE SAY IX-1 LIKE?
(LSF, 35, 6 b , c)

1 WHO PIERRE SAY IX-1 LIKE WHO ? (LSF, 35, 8 b)

We conclude that for our main LSF consultant wh-extraction out of Attitude Role Shift is not permissible.

\subsection{Conclusion and further controls}

In Section 3, it seemed that Attitude Role Shift in ASL offers a good case for a context-shifting analysis: the $w h$-extraction test suggests that the examples under investigation do not involve standard (clausal) quotation; and the fine-grained interpretation of indexicals under Role Shift suggests that they genuinely have a shifted, De Se interpretation. By contrast, our main LSF consultant does not seem to allow for wh-extraction out of a role-shifted clause. This might show (i) that these have a pure quotational semantics; or (ii) that they don't have a quotational semantics, but that these role-shifted clauses are in a syntactic position from which material cannot be extracted; or (iii) that some other condition forces a quotational reading. (We will argue in Part II that the correct solution is (iii): the semantics of Role Shift involves context shift, but it has a quotational component that seems to be more rigid for our LSF consultant than for our ASL consultant.)

Even for ASL, however, three cautionary notes should be added.

1. We discuss in Appendix II the behavior of the apparently quotational operator " " in ASL. In brief: (i) in our data, it behaves in every respect like Attitude Role Shift, except that it requires more of a context to be licensed; (ii) this might suggest that quotation does allow for wh-extraction in ASL. But the inference needn't

20 This is the average of 2 judgments, as shown in Appendix IV. We got 2 additional judgments on a similar sentence filmed as part of video 35,8 , and in each case the sentence was given a 1 . 
Super monsters I

go through: pending further investigation, it might also be that the 'quotational' operator in fact involves a variety of Role Shift (this possibility becomes more likely in view of results laid out in in Part II, where we argue that Role Shift simultaneously involves Role Shift and a quotational/iconic component; but it must also be said that our cases of quotation do not seem to involve body shift, unlike our cases of Role Shift).

2. Even if we restrict attention to ASL and set aside the point in 1., it must be acknowledged that an analysis of the facts without context shift is possible: one could argue that ASL Role Shift allows for partial quotation, for instance along the lines of Maier, to appear. The idea would be that a role-shifted clause under an attitude verb is syntactically integrated, but that for whatever reasons Role Shift is an instruction to read as much as possible of that clause with partial quotation.

3. Finally, it turns out that our main ASL consultant has a word, $A N Y$, which in some contexts displays a bona fide NPI behavior. We tested ASL counterparts of the integration test in (5). Unsurprisingly, in the absence of Role Shift, licensing from a matrix negation into the embedded clause was possible, just as in English. But with Role Shift the result was degraded, which argues for the opposite conclusion from the one we reached on the basis of $w h$-extraction test. We will discuss these data and their theoretical consequences in Part II.

\section{The importance of Action Role Shift}

The upshot of our discussion of Attitude Role Shift is that some tests - notably wh-extraction in ASL - suggest that it is syntactically integrated in a way that quoted sentences in English are not. But the same facts didn't hold in LSF, and even in ASL the cautionary remarks made in Section 4.3 and in Appendix II suggest that our conclusions are provisional at best.

These difficulties might pave the way for an analysis of Role Shift in terms of partial (i.e. less-than-clausal) quotation, for instance along the lines discussed Maier 2014, to appear. We believe that this conclusion would be incorrect. Our argument is as follows:

(i) Unlike Attitude Role Shift, Action Role Shift could not be analyzed in terms of quotation, for the simple reason that it is often used to describe situations that involve no propositional attitude whatsoever. For these cases, a mechanism akin to context shift must be posited.

(ii) Once this mechanism is in place for Action Role Shift, a minor modification of it can account for Attitude Role Shift. 
(iii) In addition, we will see in Part II that both versions of the mechanism must be supplemented with an iconic component, whereby elements that can be interpreted iconically in the scope of a Role Shift operator must be attributed to the role-shifted context. We will argue that this general mechanism derives as a special cases the quotational component of Attitude Role Shift, while also accounting for the iconic but non-quotational component of Action Role Shift.

In the rest of this section, we motivate the conclusion in (i). The context-shifting component of the analysis is developed in Section 7, while the necessity of adding an iconic component is developed in Part II.

A terminological note is in order at this point. What we call 'Action Role Shift' is usually termed 'constructed action' in the sign language literature. Here is for instance how Lillo-Martin \& de Quadros 2011 introduce the notion (see also S. K. Liddell \& Metzger 1998 for a justification of the terminology):

"The non-quotative use of RS [= Role Shift -PS] reconstructs not the words/thoughts, but the actions of a particular referent. It has come to be known as constructed action (CA) (Liddell and Metzger, 1998). (...) Such examples often combine lexical signs, classifier signs, and (non-sign) mimics and gestures, along with facial expressions and body positions to represent those of the character whose actions are being described. The non- manual markings generally include mimicking the facial expression of the character; an actual shift of the position of the shoulders may or may not be seen. The shoulder shift is most likely to appear in quotational RS."

But the terminology is in part ambiguous. For instance, Metzger 1995 notes that "evidence suggests that in ASL, constructed dialogue is a form of constructed action", which might blur the distinction between action and attitude reports - a distinction which remains important, in part because attitude reports with Role Shift have different grammatical properties from action reports with Role Shift. To emphasize the fact that Role Shift is involved in both cases (as defined by Quer, to appear, cited above), we prefer to use the terms 'Attitude Role Shift' for instances of the operation that serve to report a thought or speech act, and 'Action Role Shift' for instance that serve to report a non-attitudinal action. 
Super monsters I

\subsection{Basic properties of Action Role Shift in ASL}

A simple example of Action Role Shift in ASL is given in (28b), which contrasts with indirect discourse report in (28a). ${ }^{21}$

(28) IX-a JOHN OFTEN MEET-MEET [POOR PEOPLE $]_{\mathrm{b}}$, IX-1 KNOW LOTS PEOPLE IX-arc-b IX-a FINISH

'John often meets poor people. I know lots of people that he

\section{a. 7 ?-GIVE-b-rep MONEY.}

has given money to.'

b. $7 \frac{\mathrm{RS}_{\mathrm{a}}}{1-\text { GIVE-b-rep MONEY. }}$

has given money to.'

(ASL, 18, 98)

The same data are replicated in (29a) and (29b), but in the scope of a negative quantifier - which clearly shows that Action Role Shift can arise under binding, as the argument of GIVE couldn't be deictic (since the quantifier in (28) is positive, it is a bit less easy to exclude a deictic reading with a plural denotation for the argument of GIVE; note that Attitude Role Shift can also arise in the scope of quantifiers, as shown in Appendix I). A negative sentence with Action Role Shift seems to lead to slightly degraded acceptability for our ASL consultant, but the result is still on the 'acceptable' side.

(29) IX-a JOHN OFTEN MEET-MEET [POOR PEOPLE $]_{\mathrm{b}}$, BUT IX-1 NOTKNOW ANYONE IX-arc-b IX-a FINISH

'John often meets poor people, but I don't know any of them he
a. 6.8 a-GIVE-b MONEY. has given money to.'
b. $6 \frac{\mathrm{RS}_{\mathrm{a}}}{1-\text { GIVE-b MONEY. }}$ has given money to.'

(ASL, 14, 108)

In (28b) and (29b), the signer shifts his body to adopt John's position, in locus $a$, in the realization of the verb give. As a result, this verb appears with a (shifted) first person agreement marker. In addition, this clause is clearly integrated with the rest

21 Note, however, that the indirect discourse control in (28a) is imperfect. As J. Lamberton (p.c.) remarks, it involves a small rotation of the head, without the full body shift seen in the role-shifted example in (28b). The origin of GIVE in this sentence is intermediate between locus $a$ (which would expected for indirect discourse) and a kind of role-shifted first person locus; due to this uncertainty, we have written: ?-GIVE- $b$. 
of the discourse, since the object of GIVE (corresponding to locus $b$ ) is bound by a quantifier.

A minimal contrast between Attitude Role and Action Role Shift is presented for ASL in (30). In (30a), an instance of Attitude Role Shift, the signer shifts his body to adopt the position of the arrogant French swimmer (in locus $a$ ) right after the verb $S A Y$. In (30b), which reports an action rather than a speech or thought act, no attitude verb is used, and Role Shift starts after the third person pronoun $I X-a$. In both cases, a first person pronoun or agreement marker appears inside the role-shifted clause, and is interpreted with respect to the shifted context. ${ }^{22}$ For comparison, both sentences are signed without Role Shift at all in (31).

SEE [THAT ARROGANT FRENCH SWIMMER] IX-a? YESTERDAY IX-a ANGRY $_{\mathrm{a}}$.

'Do you see that arrogant French swimmer? Yesterday he was angry.

a. 6.2 IX-a SAY IX-1 WILL LEAVE.

He said: 'I will leave."

$\mathrm{RS}_{\mathrm{a}}$

b. 7 IX-a 1-WALK-WITH-ENERGY(CL-ONE).

He walked away with energy.'

(ASL, 14, 233)

(31) SEE [THAT ARROGANT FRENCH SWIMMER] IX-a? YESTERDAY IX-a ANGRY .

'Do you see that arrogant French swimmer? Yesterday he was angry.

a. 7 IX-a SAY IX-a WILL LEAVE

He said he would leave.'

b. 7 IX-a WALK-WITH-ENERGY(CL-ONE)

He walked away with energy.'

(ASL, 14, 231)

It should be noted that there are ill-understood constraints on Action Role Shift, which is not acceptable in all contexts. One possibility is that it must be justified by the fact that some expressions within its scope are interpreted iconically - which is the case of the classifier construction WALK-WITH-ENERGY(CL-ONE) in (31b), where the finger classifier operates a movement that can be taken to represent that of the angry swimmer. This is also the case of the example in (32b), where the sign for 'break down' has a clear iconic component. We will come back to this point

22 Additional sentences in this video $(14,233)$, which involved a happy face on the part of the speaker, are discussed in Part II. 
Super monsters I

in Part II (we will argue that role-shifted clauses must be interpreted 'maximally iconically', and we will leave open whether there is also requirement that something in them should be interpreted iconically).

a. 7 SEE IX-a ARROGANT FRANCE SWIMMER. YESTERDAY IX-a ANGRY, IX-a DOOR PUNCH-rep, [BREAK DOWN]-CL+rep.

$\Rightarrow$ the French swimmer did/will in fact break doors.

'Did you see that arrogant French swimmer? Yesterday he was angry, he was breaking down doors.'

b. 7 SEE IX-a ARROGANT FRANCE SWIMMER. YESTERDAY IX-a ANGRY, IX-a DOOR PUNCH-rep, [BREAK DOWN]-CL+rep.

$\Rightarrow$ the French swimmer did/will in fact break doors.

'Did you see that arrogant French swimmer? Yesterday he was angry, he was breaking down doors.'

(ASL, 18, 102)

Importantly, we included in some of the trials for (32) an inferential task designed to determine whether the sentence was understood as an action report or as an attitude report. ${ }^{23}$ In this respect, there was no contrast between the sentence with $(=(32 a))$ and without Role Shift (= (32b)): both were understood with an actuality entailment, to the effect that doors were or would in fact be broken.

\subsection{Constraints on indexicals in ASL}

\subsubsection{IX-1}

It was noticed in the literature that Action Role Shift (= 'non-quotative role shift' or in some uses 'constructed action') differs from Attitude Role Shift (= 'quotative role shift') in that full first person pronouns are acceptable with a shifted reference in the latter context but not in the former; by contrast, first person agreement markers are acceptable with a shifted reference in both environments. In their review of the literature, Lillo-Martin \& de Quadros 2011 provide the following minimal pair, where the translation makes clear that (33a) is interpreted as an attitude report whereas (33b) is interpreted as an action report (we keep the authors' transcription conventions). Importantly, ASL quite generally has the ability to interpret Role Shift as an attitude report without an overt attitude verb, and thus the possibility of such an interpretation is not particularly surprising. What is crucial, by contrast, is that

23 As shown in Appendix IV, the question was: Do we understand that the French swimmer (i) said he was breaking/would break doors? (ii) did/will in fact break doors? 
this interpretation should be obligatory when a full first person pronoun (as opposed to a first person agreement marker) is used.

a. FRIEND (SAY) $\overline{<b-O L Y M P I C S}$, IX (self) 1-WATCH-b> 'My friend was like, "the Olympics, I watch.",

RS:friend

b. FRIEND, $\overline{b-O L Y M P I C S}<1-$ WATCH-b $>$

'My friend was watching the Olympics.'

(ASL, Lillo-Martin \& de Quadros 2011)

This pattern is replicated in our own data. In (34) and (35), we compared examples with first person vs. null pronouns in subject and possessor positions. As soon as a first person subject pronoun was used, an attitude reinterpretation arose; the same effect was seen, less clearly, when a first person possessive pronoun was used in the absence of a first person subject pronoun. As in other cases, the interpretive effect was established by way of an inferential task, with the question: Do we understand that John (i) said he was emailing people? (ii) did/will in fact email people?. Answers differed across the paradigm in (34) (see Appendix IV for details).

YESTERDAY IX-1 1, a-MEET JOHN / $^{\text {1-MEET IX-a JOHN }}{ }^{24}$. IX-a

'Yesterday I met John. He
$\mathrm{RS}_{\mathrm{a}}$
a. $6 \overline{1-E M A I L-r e p ~ F R I E N D S . ~}$
$\Rightarrow$ John did/will email people ${ }^{25}$
was emailing his friends.'
b. $\quad 3.7 \frac{\mathrm{RS}_{\mathrm{a}}}{1-E M A I L-r e p ~ P O S S-1 ~ F R I E N D . ~}$ judgments in Appendix IV)
said he was emailing his friends.'
c. $\quad 5.7 \stackrel{\mathrm{RS}_{\mathrm{a}}}{\mathrm{IX}-1 \text { 1-EMAIL-rep FRIENDS. }}$
said he was emailing his friends.'
$\Rightarrow$ John said he was emailing people

$\Rightarrow$ John said he was emailing people (but see the detailed inferential

24 The first version was signed in(a), the second in (b), (c), (d); note that 1-MEET seems to display subject agreement but not object agreement.

25 The inferential question (which appears in Appendix IV) pertained to 'emailing people', which is why we use this formulation (rather than 'emailing friends') in our description of the inferences obtained. 
Super monsters I

$\mathrm{RS}_{\mathrm{a}}$

d. 6 IX-1 1-EMAIL-rep POSS-1 FRIEND.

$\Rightarrow$ John said he was emailing people

said he was emailing his friends.'

(ASL, 19, 214)

(35) YESTERDAY IX-1 MEET IX-a JOHN

'Yesterday I met John. He

$\mathrm{RS}_{\mathrm{a}}$

a. 6.3 1-CONTACT-rep-arc FRIEND.

$\Rightarrow$ John $\mathrm{did} /$ will in fact contact people

was contacting his friends.'

$\mathrm{RS}_{\mathrm{a}}$

b. $\quad 3.3$ 1-CONTACT-rep-arc POSS-1 FRIEND.

[unclear whether John said he was contacting people, or did/will in fact contact people; possibly the former]

[It is unclear whether this is an attitude or an action report.]

$\mathrm{RS}_{\mathrm{a}}$

c. $\quad$ 5.3 IX-1 1-CONTACT-rep-arc FRIEND.

$\Rightarrow$ John said he was contacting people

said he was contacting his friends.'

$\mathrm{RS}_{\mathrm{a}}$

d. 6 IX-1 1-CONTACT-rep-arc POSS-1 FRIEND.

$\Rightarrow$ John said he was contacting people

said he was contacting his friends.'

(ASL, 19, 218)

The same generalization applies to subject pronouns in the contrast between (32b) above, which did not give rise to an attitude interpretation, and (36), which does. The latter fact seems to be due to the presence of a full first person pronoun in the scope of Role Shift. ${ }^{26}$

26 The example in (36) has the advantage of making it possible to check that it is the specific presence of a first person pronoun under Role Shift, rather than the repetition of any pronoun, which is responsible for the attitude interpretation. For as seen in (ib) below, in this particular structure the repetition of a third person pronoun is compatible with an action interpretation. Hence it is likely that in (36) it is the first person nature of the pronoun that forces the attitude reinterpretation.

(i) SEE IX-a ARROGANT FRANCE SWIMMER. YESTERDAY IX-a ANGRY, IX-a DOOR 'See that arrogant French swimmer? Yesterday he was angry,

a. PUNCH-rep, [BREAK DOWN]-CL+rep and he broke down doors.' 
Philippe Schlenker

\subsection{SEE IX-a ARROGANT FRANCE SWIMMER. YESTERDAY IX-a AN- $\mathrm{RS}_{\mathrm{a}}$} GRY, IX-a DOOR IX-1 PUNCH-rep, [BREAK DOWN]-CL+rep. $\Rightarrow$ the French swimmer said he was breaking/would break down doors and he was saying that he would break doors!' (ASL, 19, 143)

It is of some importance to note that in (34) and (35) the object FRIEND is also under Role Shift. Thus it is not just the case that any non-verbal material triggers an attitude reinterpretation; rather, it seems that the first person pronoun per se is responsible for this process in the examples in which it appears under Role Shift. (We will see that our LSF consultant's judgments are in this respect different - he often dislikes any non-verbal material under Role Shift unless it comes with an attitude interpretation.)

It is interesting to investigate whether other indexicals give rise to similar contrasts. An initial investigation suggests that with our main ASL consultant TOMORROW triggers an attitude reinterpretation, and HERE and NOW MORNING sometimes do. In all cases, indexicals received a shifted interpretation under Role Shift (and sometimes outside of Role Shift too).

\subsubsection{HERE}

(37a) and (37b) show that HERE displays the behavior of an indexical (rather than of an anaphoric expression) when it appears outside of Role Shift: in such cases, it must refer to the place of utterance (= Paris, because the sentences were elicited while our ASL consultant was in Paris). (37a) and (38b) show that HERE is acceptable under Attitude Role Shift, but also under Action Role Shift (though it seems to be a bit less acceptable there). When it comes to interpretation, our consultant's judgments were unstable: in Action Role Shift, HERE sometimes did and sometimes did not give rise to an attitude reinterpretation, as can be seen in the full ratings provided in Appendix IV. Of course in Attitude Role Shift the data are simpler: an attitude reading was always obtained, and both indexicals (IX-1 and HERE) received a shifted interpretation. Here and throughout, the translation of the indexicals (and in particular the fact that they are obligatorily shifted under Role Shift) is motivated by inferential questions that appear in Appendix IV.

b. IX-a PUNCH-rep, [BREAK DOWN]-CL+re and he broke down doors.'

(ASL, 19, 174) 
Super monsters I

(37) Context: The sentences were elicited in Paris.

a. 7 SEE IX-a ARROGANT FRANCE SWIMMER. YESTERDAY LONDON IX-a ANGRY, IX-a DOOR HERE PUNCH-rep [BREAK DOWN]CL+rep.

$\Rightarrow$ the French swimmer did in fact break doors

'See that arrogant French swimmer? Yesterday in London he was angry. He broke down doors here [= in Paris].'

b. 5.6 SEE IX-a ARROGANT FRANCE SWIMMER. YESTERDAY LONDON IX-a ANGRY, IX-a

$\mathrm{RS}_{\mathrm{a}}$

DOOR HERE 1-PUNCH-REP, [BREAK DOWN]-CL+rep.

$\Rightarrow$ unstable judgments: the French swimmer said he was breaking doors / did in fact break doors

'See that arrogant French swimmer? Yesterday in London he was angry. He broke down doors there [= in London] / he said: 'I (will) break doors here [= in London].'

(ASL, 18, 117)

(38) Context: The sentences were elicited in Paris.

a. 7 SEE IX-a ARROGANT FRANCE SWIMMER. YESTERDAY LONDON IX-a ANGRY, IX-a SAY DOOR HERE IX-a PUNCH-REP [BREAK DOWN]-CL-rep.

'See that arrogant French swimmer? Yesterday in London he was angry, he said he would break doors here [= in Paris].'

b. 7 SEE IX-a ARROGANT FRANCE SWIMMER. YESTERDAY LONDON IX-A ANGRY, IX-A SAY

$\mathrm{RS}_{\mathrm{a}}$

DOOR HERE IX-1 PUNCH-rep, [BREAK DOWN]-CL-rep.

'See that arrogant French swimmer? Yesterday in London he was angry, he said he would break doors there [= in London].'

(ASL, 18, 109)

\subsubsection{NOW MORNING [= 'this morning']}

The generalizations are similar with NOW MORNING [= 'this morning']: without Role Shift, it behaves like a standard indexical; under Role Shift, it receives a shifted interpretation, but it is unclear whether it triggers an attitude reinterpretation (judgments were not stable). In addition, it must be observed that under Action Role Shift NOW MORNING is a bit degraded. 
Philippe Schlenker

(39) a. 7 SEE IX-a ARROGANT FRANCE SWIMMER. YESTERDAY LONDON IX-a ANGRY, IX-a NOW MORNING DOOR PUNCH-rep [BREAK DOWN]-CL-rep $\Rightarrow$ the French swimmer did/will in fact break doors

'See that arrogant French swimmer? Yesterday in London he was angry, and this morning [= today] he broke down doors.'

b. 5 SEE IX-a ARROGANT FRANCE SWIMMER. YESTERDAY LONDON IX-a ANGRY, IX-a

$\mathrm{RS}_{\mathrm{a}}$

NOW MORNING DOOR PUNCH-rep, [BREAK DOWN]-CL-rep.

$\Rightarrow$ unclear inferences: the French swimmer said he was breaking/would break doors /did/will in fact break doors.

'See that arrogant French swimmer? Yesterday in London he was angry, and yesterday morning he broke doors. / he said: 'I will break down doors."

(ASL, 19, 165)

(40) a. 7 SEE IX-a ARROGANT FRANCE SWIMMER. YESTERDAY LONDON IX-a ANGRY, IX-a SAY NOW MORNING DOOR IX-a PUNCHREP [BREAK DOWN]-CL-rep.

'See that arrogant French swimmer? Yesterday in London he was angry, he said that this morning [= today] he would break doors.'

b. 7 SEE IX-a ARROGANT FRANCE SWIMMER. YESTERDAY LONDON IX-a ANGRY, IX-a SAY NOW MORNING DOOR IX-1PUNCH-REP, [BREAK DOWN 'See that arrogant French swimmer? Yesterday in London he was angry, he said: 'This morning [= yesterday from the speaker's perspective] I am breaking/broke/will break doors"

(ASL 19, 164)

\subsubsection{TOMORROW}

Under Action Role Shift, TOMORROW triggers an attitude reinterpretation, and also receives a shifted reading, as shown in (41b) (note that the control sentence in (41a) is degraded, and that the interpretation of TOMORROW is unclear). Under Attitude Role Shift, TOMORROW systematically receives a shifted interpretation, as shown in (42).

(41) a. 4.8 SEE IX-a ARROGANT FRANCE SWIMMER. YESTERDAY LONDON IX-a ANGRY, IX-a TOMORROW DOOR PUNCH-rep [BREAK DOWN]-CL-rep. 
Super monsters I

'See that arrogant French swimmer? Yesterday in London he was angry. [Today? tomorrow?] he is/will be breaking down doors.'

b. 6 SEE IX-a ARROGANT FRANCE SWIMMER. YESTERDAY LONDON IX-a ANGRY, IX-a

$\mathrm{RS}_{\mathrm{a}}$

TOMORROW DOOR 1-PUNCH-rep, [BREAK DOWN]-CL-rep.

'See that arrogant French swimmer? Yesterday in London he was angry. He said: 'Tomorrow I will break down doors."

(ASL, 18, 119)

a. 6.7 SEE IX-a ARROGANT FRANCE SWIMMER. YESTERDAY LONDON IX-a ANGRY, IX-a SAY TOMORROW DOOR IX-a PUNCH-rep [BREAK DOWN]-CL-rep.

'See that arrogant French swimmer? Yesterday in London he was angry. He said that tomorrow he would break doors.'

b. 7 SEE IX-a ARROGANT FRANCE SWIMMER. YESTERDAY LONDON IX-a ANGRY, IX-a SAY

$\mathrm{RS}_{\mathrm{a}}$

TOMORROW DOOR IX-1 PUNCH-rep, [BREAK DOWN]-CL-rep.

'See that arrogant French swimmer? Yesterday in London he was angry. He said: 'Tomorrow I will break doors."

(ASL, 18, 111)

We conclude that the first person agreement marker is shiftable under Action Role Shift, that the full first person pronoun triggers an attitude reinterpretation, and that the other indexicals we tested behave like the full first person pronoun or give rise to unstable judgments.

\subsection{Action Role Shift in ASL}

Our data about Action Role Shift in LSF are more complex. In brief:

1. In the absence of overt attitude reports, Role Shift is possible in LSF. In some cases, it is understood as an action report - thus Action Role Shift clearly exists in LSF.

2. At least some instances of Action Role Shift involve agreement verbs, with the effect that first person agreement markers are interpreted with respect to a shifted context.

3. In some cases, Role Shift without an attitude operator is still understood as an attitude report (we even have a case of a mixed interpretation involving both an 
action and an attitude; see (45b)). Usually overt indexicals trigger an attitude reinterpretation, and are obligatorily shifted.

4. But many things appear to trigger an attitude interpretation of Role Shift. In some cases, nouns under Role Shift trigger this reinterpretation; and in some of our examples, there are minimal contrasts among bare verbs, with some triggering an attitude reinterpretation, and others not.

Due to 3., we cannot draw strong conclusions from the fact that overt indexicals trigger an attitude reinterpretation: this might be due to their overt nature, or to the fact that they are indexicals, though in some cases it seems that indexicals per se trigger the reinterpretation, as we will see shortly. It is worth adding that in virtually all the cases we have considered, when indexicals are acceptable under Role Shift, they have a shifted meaning. ${ }^{27}$

To illustrate points 1 and 2, consider (43b), which is a role-shifted version of (43a).
a. 7 WOLF IX-a SHEEP a,b-THE-TWO FRIEND. LAST-YEAR IX-a HUNGRY. IX-a a-CATCH-b EAT-rep.
'The wolf and the sheep are friends. Last year, the wolf was hungry. He caught the sheep and ate it.'
b. 6.7 WOLF IX-a SHEEP FRIEND a,b-THE-TWO. LAST-YEAR IX-a $\mathrm{RS}_{\mathrm{a}}$ HUNGRY. IX-a 1-CATCH-b DEVOUR-rep.
'The wolf and the sheep are friends. Last year, the wolf was hungry. He caught the sheep and devoured it.'
(LSF, 37, 53; similar video and similar judgment in 40, 74)

27 In one session, the example in (i) was an exception to this generalization (see also fn. 31 for another possible exception). But this judgment appears to be an outlier: in the other 3 sessions in which the paradigm was tested, the judgments patterned with our generalization (what complicates matters is that in some cases HERE is unshifted when it appears outside of Role Shift [video 39, 46]).

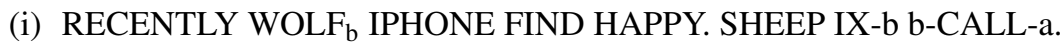
a. 7 IX-b $\overline{\text { IPHONE HERE 1-SHOW-a }}$. (HERE = unshifted in 1 session; shifted in 3 sessions.) $\mathrm{RS}_{\mathrm{a}}$
b. 7 IX-b IPHONE HERE 1-SHOW-CL-a. $(H E R E=$ unshifted in 1 session; shifted in 3 ses- sions.)

'Recently the wolf was happy to find an iPhone. He called the sheep - and there [or: here] showed him the iPhone.'

(LSF, 39, 32) 
Super monsters I

$C A T C H$ is an agreement verb, realized with a different origin in the first and in the third person; and as far as we can tell, in the role-shifted version the movement starts from the signer's role-shifted position. ${ }^{28}$ Importantly, the inference our consultant obtained is that the wolf in fact caught the sheep, which suggests that in this case an attitude reinterpretation is not obligatory (nor necessarily possible).

To illustrate points 3. and 4., consider the following paradigms. In (44), an allpurpose verb $S H O W$ is compared with a classifier verb $S H O W-C L$, which displays the hand position with which the relevant object was held and shown. The classifier verb $\mathrm{SHOW}$-CL is entirely acceptable under Action Role Shift, with an inference that the action in fact took place; the all-purpose verb $S H O W$ is less acceptable, ${ }^{29}$ and it is unclear whether it gives rise to an attitude reinterpretation.

(44) RECENTLY WOLF IPHONE FIND $_{c}$ HAPPY. SHEEP $a$ IX-b b-CALL-a. 'Recently the wolf was happy to find an iPhone. He called the sheep.

\section{a. 4.3 IX-b IPHONE $\frac{\mathrm{RS}_{\mathrm{b}}}{1-\mathrm{SHOW}-\mathrm{a}}$.}

$\Rightarrow$ unclear inference

He [= the wolf] showed [or: said/thought he was showing/would show] the iPhone to him.'

b. 7 IX-b IPHONE $\frac{\mathrm{RS}_{\mathrm{b}}}{1-\mathrm{SHOW}-\mathrm{CL}-\mathrm{a} \text {. }}$

$\Rightarrow$ the wolf in fact showed the iPhone to the sheep

He [= the wolf] showed the iPhone to him.'

(LSF, 39, 26)

In (45), IPHONE is signed under Role Shift, with the same verbs SHOW and SHOW$C L$. Both sentences are now acceptable, but both give rise to a partial or total attitude reinterpretation.

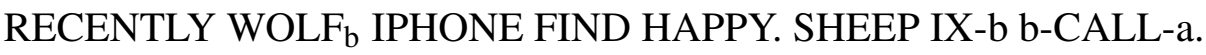

'Recently the wolf was happy to find an iPhone. He called the sheep.

$$
\mathrm{RS}_{\mathrm{b}}
$$

a. $\quad$ 6.7 IX-b IPHONE 1-SHOW-a.

$\Rightarrow$ the wolf said/thought he was showing/would show the iPhone to him

$\mathrm{He}$ [= the wolf] said/thought he would show/was showing the iPhone to him.'

\footnotetext{
28 We write 'as far as we can tell' because this is not a trivial judgment to make: in standard first person examples the movement starts from a position close the signer's chest; under Role Shift as in (43b), this is less clear.

29 In one session, our consultant mentioned that in this case one doesn't understand what justifies Role Shift.
} 
b. 7 IX-b $\frac{\mathrm{RS}_{\mathrm{b}}}{\mathrm{IPHONE} \text { 1-SHOW-CL-a. }}$

$\Rightarrow$ the wolf said 'iPhone' and showed the iPhone (see full ratings in Appendix IV)

He [ = the wolf] said '(an) iPhone' and showed it.'

(LSF, 39, 37; see also LSF, 39, 27)

In (45a), a simple attitude reinterpretation is obtained; in (45b), our consultant gave a mixed response, and explained that 'iPhone' was quoted but that the action of showing it was real - which he illustrated with an example of a scene in which the wolf said 'Oh an iPhone', picked it up and showed it. ${ }^{30}$ When a full first person pronoun is included under Role Shift, as in (46), a full attitude reinterpretation is obtained. $^{31}$

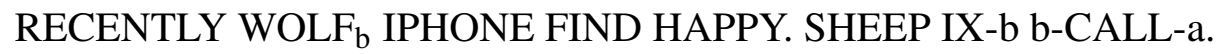

'Recently the wolf was happy to find an iPhone. He called the sheep.

a. 6 IX-b IPHONE $\frac{\mathrm{RS}_{\mathrm{b}}}{\mathrm{IX}-1 \text { 1-SHOW-a. }}$ $\Rightarrow$ the wolf said/thought he was showing/would show the iPhone to him $\mathrm{He}$ [= the wolf] said/thought he would show/was showing the iPhone to him.'

b. 6 IX-b IPHONE $\frac{\mathrm{RS}_{\mathrm{b}}}{\mathrm{IX}-1 \text { 1-SHOW-CL-a. }}$ $\Rightarrow$ the wolf said/thought he was showing/would show the iPhone to him $\mathrm{He}$ [= the wolf] said/thought he would show/was showing the iPhone to him.'

(LSF, 39, 28)

Finally, in some cases the presence of an indexical per se seems to play a role in triggering an attitude reinterpretation under Role Shift. Thus in (47a), despite the

30 This was in particular recorded in the explanations given in video 40, 50. Note that in our recent sessions on Action Role Shift, we took two measures to clarify the inferential judgments. First, we asked our consultant to give possible examples of the scenes that were reported. Second, we sometimes asked our consultant to briefly repeat the (written) inferential question in LSF at the beginning of the signed version of his answer so as to make sure that there was no ambiguity in that question.

31 As shown in Appendix IV, in one session our consultant gave low ratings $(=4)$ to both sentences, saying that there was an ambiguity as to who $I X-1$ referred to (= the wolf or the signer).

We should add that we have further examples in which an attitude reinterpretation is triggered by a possessive first person pronoun rather than by an embedded subject first person pronoun. Specifically, in modifications of (43b) in which SHEEP or FRIEND POSS-1 is added as the object of DEVOUR under Role Shift, SHEEP gives rise to an unclear interpretation (action or attitude report depending on the session), whereas FRIEND POSS-1 triggers an attitude reinterpretation (video 37, 62 vs. 37 , 60). 
Super monsters I

presence of the noun DOOR under Role Shift, the sentence is interpreted as an action report; but the minimally different (47b) tends to be interpreted as an attitude report instead, presumably because a first person possessive pronoun now appears under Role Shift. $^{32}$

IX-2 SEE SWIMMER GERMAN ARROGANT? YESTERDAY IX-a FURIOUS.

'You see that arrogant German swimmer? Yesterday he was furious.
$\mathrm{RS}_{\mathrm{a}}$
a. 6.5 FOR-THIS IX-a GO-BALLISTIC IX-a HOUSE DOOR BREAK OPEN.
$\Rightarrow$ the arrogant German swimmer in fact broke the door
That's why he went ballistic and broke open the house door.'
$\mathrm{RS}_{\mathrm{a}}$
b. 7 FOR-THIS IX-a GO-BALLISTIC IX-a HOUSE POSS-1 DOOR BREAK OPEN.
$\Rightarrow$ the arrogant German swimmer said that he was breaking (3 trials) / did in fact break the door (1 trial)
That's why he went ballistic and said: 'I am breaking open the door of my house."
(LSF, 36, 72; see also 35, 62 $2^{33}$ )

These results should be taken as preliminary. First, the contrast between the two versions of 'show' ( $\mathrm{SHOW}$ vs. SHOW-CL) will not follow from anything in Part I of this study - although we will revisit this contrast in Part II (in brief, we will argue that the iconic dimension of $S H O W-C L$ might be responsible for its acceptability under Action Role Shift). Second, it is equally unclear why IPHONE under Role Shift triggers an attitude reinterpretation - and we will only begin to address the problem in Part II. Third, our consultant's answers to inferential questions were in some cases less stable than in other cases we have studied, which suggests that some sentences might be ambiguous or that our inferential questions were suboptimal. ${ }^{34}$ Finally, we have quite a few cases in which a full indexical appears under Role Shift without an overt attitude operator, and the resulting sentence is just deviant, instead of giving rise to an attitude reinterpretation. Examples are given in (48)-(49).

32 In (53) and (54), it is not clear whether BREAK is a plain verb or an agreement (namely l-BREAK) verb.

33 Video 35, 62 involved similar sentences signed with more neutral facial expressions than 36, 72. Acceptability ratings were on average lower, less consistent, and inferential judgments were unclear. We leave an analysis of the difference between the two videos for future research.

34 In more recent iterations of the judgments, we asked our consultant to summarize the questions at the beginning of the videos in which the judgments were recorded; this should provide in the future a way to check whether the questions were at fault. 
(48a) is a simple instance of Action Role Shift, understood as an action report. In (48b) and in (49a) and (49b), various overt indexicals are added, and all lead to decreased acceptability (whether this is because they are non- verbal or because they are indexical is left open here). For whatever reason, a mechanism of attitude reinterpretation does not appear to be readily available in this case. ${ }^{35}$ Clearly, more work will be needed on Action Role Shift in LSF.

(48) IX-2 SEE SWIMMER GERMAN ARROGANT? YESTERDAY IX-a FURIOUS.

'You see that arrogant German swimmer? Yesterday he was furious.
a. 6.6 FOR-THIS IX-a DOOR BREAK.
$\Rightarrow$ the German swimmer did break the door
That's why he broke a door!'
b. 3 FOR-THIS IX-a DOOR IX-1 BREAK.
(LSF, 32, 20)
(49) IX-2 SEE SWIMMER GERMAN ARROGANT? YESTERDAY PLACE LONDON IX-a FURIOUS.
a. 1.5 FOR-THIS IX-a DOOR
b. 1.5 FOR-THIS IX-a DOOR
(LSF, 32, 31)

\section{Obligatory shifting and Shift Together}

\subsection{Varieties of context shift across sign languages}

We have now seen several patterns of context shift across sign languages.

- In Catalan and in German Sign Language (LSC and DGS), earlier investigators found examples in which under Attitude Role Shift a given clause contains (i) one indexical with a shifted meaning, and (ii) another indexical with a non-shifted meaning. Furthermore, some indexicals appear to be obligatorily shifted, while others may be evaluated with respect to the actual context or with respect to a shifted context. These data cannot be explained on the assumption that Attitude Role Shift is just standard (clausal) quotation. While they might be explained by the hypothesis that Attitude Role Shift

35 It is likely that the precise choice of non-manuals is crucial in triggering an attitude reinterpretation. We leave this question for future research. 
Super monsters I

involves partial quotation, the latter would need to be parametrized in order to explain why some expressions can be partially quoted but others cannot be (this is non-trivial: standard theories of quotation or partial quotation do not draw a distinction between 'quotable' and 'non-quotable' expressions).

- In ASL, all the indexicals we investigated are obligatorily shifted when they appear under Role Shift. The data we considered are thus harder to distinguish from standard (clausal) quotation. But we found two arguments against a simple quotational analysis: (i) it does not easily account for the fact that wh-extraction is possible out of a role-shifted clause - an argument which is weakened, however, by the fact that the quotation operator " " seems to allow for wh-extraction as well (see Appendix II) ; (ii) more importantly, the quotational analysis fails to extend to Action Role Shift, which displays some of the same properties as Attitude Role Shift but does not involve any speech or thought reports.

- In LSF, just as in ASL, acceptable indexicals that appear under Attitude Role Shift must have a shifted interpretation. Unlike what we found in ASL, the wh-extraction test (= argument (i)) failed to show that these constructions are not instances of simple quotation. Still, the existence of Action Role Shift (= argument (ii)) yields an indirect — if weaker — argument against a simple quotational analysis.

Our generalizations about ASL and LSF can be stated more precisely as follows:

Role Shift and Context Shift in ASL and LSF

a. ASL and LSF allow for Attitude Role Shift and Action Role Shift.

b. All indexicals can appear under Attitude Role Shift in both languages, and all must have a shifted reading.

c. First person agreement verbs can appear under Action Role Shift in both languages, and they obligatorily have a shifted interpretation. Other indexicals display different patterns:

- Several indexicals in ASL trigger an attitude reinterpretation when they appear under Role Shift without an attitude verb.

- LSF indexicals in LSF sometimes trigger an attitude reinterpretation; sometimes they are unacceptable; and sometimes their interpretation (shifted vs. unshifted) is unclear.

Interestingly, LSC and DGS on the one hand and ASL and LSF on the other differ along a dimension that has been important in studies of context-shift in spoken languages. In one type (LSC and DGS), different indexicals may be evaluated with respect to different contexts. In the other (ASL and LSF) all indexicals that are 
acceptable must be evaluated with respect to the same context - a point to which we turn in Sections 6.2 and 6.3.

\subsection{Shift Together in spoken languages ${ }^{36}$}

In important work, Anand \& Nevins 2004 and Anand 2006 showed that in Zazaki, an Indo-Aryan language of Turkey, some verbs are bona fide context-shifting operators. But they argued that when the context of evaluation of a clause is shifted, all the indexicals that are found in it must be evaluated with respect to the same context - a constraint they labeled 'Shift Together':

(51) Shift Together (Anand \& Nevins 2004)

If an indexical is shifted in the scope of a modal operator, all other indexicals in the same clause must be shifted as well.

$\ldots$ attitude verb..$\delta\left[\ldots\right.$ shifted indexical $_{1} \ldots$ shifted indexical $\left.{ }_{2} \ldots\right]$

Importantly, they showed that standard quotation could not account for their data because shifted indexicals could co-occur with $w h$-extraction or NPI licensing from outside the embedded clause, as shown in (52) and (53) (it can be shown independently that kes is indeed a negative polarity item):

(52) Extraction in Zazaki

a. čencke [ke Heseni va mi $t$ paci kerda] rindeka girl that Hesen said I $t$ kiss did pretty.de-PRES

'The girl that Hesen said \{Hesen, I\} kissed is pretty.' (Anand and Nevins, 2004)

b. Piyaa-o [ke Rojda va ke mi $t$ paci kerd] Ali biyo Person that Rojda said that I $t$ kissed did Ali was

'Ali was the person that Rojda said $\{$ Rojda, I\} kissed.'

(Anand \& Nevins 2004)

(53) NPI licensing in Zazaki

a. Rojda ne va ke mi kes paci kerd Rojda not said that I anyone kiss did

'Rojda didn't say that she kissed anyone.'

(Anand \& Nevins 2004)

36 Part of the discussion borrows in form and content from Schlenker 2011. 
Super monsters I

b. Tawa Alii va ke mi kes paci kerd

Q Ali.oBL said that I anyone kiss did

'Did Ali say that I kissed anyone?' OR

'Did Ali say that he kissed anyone?'

They showed that despite this property, embedded indexicals have to obey Shift Together:

Zazaki obeys Shift Together (Anand \& Nevins 2004)

vizeri Rojda Bill-ra va $k \varepsilon \quad$ ez to-ra miradiša yesterday Rojda Bill-to said that I you-to angry.be-PRES

"Yesterday Rojda said to Bill, "I am angry at you.",

'Yesterday Rojda said to Bill, "AUTH(c) is angry at ADDR(c).",

"*Yesterday Rojda said to Bill, "AUTH(c) is angry at you.",

"*Yesterday Rojda said to Bill, "I is angry at ADDR(c).",

(AUTH(c) and ADDR(c) refer to the author and addressee of the actual context.)

For Anand \& Nevins 2004 and Anand 2006, a covert context-shifting operator is optionally present under the verb say in Zazaki. When it is absent, the embedded clause behaves like an English clause in standard indirect discourse. When the context-shifting operator is present, it shifts the context of evaluation of all indexicals within its scope - hence the fact that we cannot 'mix perspectives' within the embedded clause.

In Schlenker 2003, by contrast, a context-shifting analysis of attitude reports was developed in which different indexicals could be evaluated with respect to different contexts. This was claimed to be the case in Amharic, where two occurrences of a first person feature that occur in the same embedded environment may be evaluated with respect to different contexts, which suggests that Shift Together fails to hold.

(55) Amharic first person pronouns (apparently) fail to obey Shift Together (Anand 2006)

John lij-e ay-ittazzəzəññ alə

John son-my NEG.3s-obey.mkimperf-1sO say.PERF.3sm

'John said, "my son will not obey AUTH(c).,'

'John said, "AUTH(c)'s son will not obey me.",

Anand (2006) re-tested these data and also reanalyzed them by positing an ambiguity: the Amharic first person marker may behave as an unshiftable indexical, or as a logophoric element, which according to Anand falls under a different generalization. Be that as it may, Schlenker 2003 also treated the Russian present tense as a shiftable indexical; if this analysis is correct, Russian must be allowed to 'mix perspectives' 
in embedded clauses. Thus in (56) the present tense is evaluated with respect to the shifted context, but the third person pronoun isn't (since it denotes the speaker of the reported context).

(56) Shifting is possible under attitude verbs [Russian]

Petja $_{i}$ skazal, čto on ${ }_{i}$ plačet

Petja $_{\mathrm{i}}$ said that he $\mathrm{e}_{\mathrm{i}}$ is-crying

'Petja said that he was crying [at the time of his utterance]'

\subsection{Shift Together in sign languages}

Interestingly, the typology we found in sign language argues for an ecumenical view - some languages enforce 'Shift Together', while others don't, and allow different indexicals that appear in the same clause to be evaluated with respect to different contexts. Specifically, Shift Together fails to hold in LSC and DGS, while it seems be in force in ASL and LSF. The difference between the spoken language data and the sign language data is that in the latter, context shift is made visible by Role Shift.

Since the ASL and LSF indexicals were obligatorily shifted when they were acceptable under Role Shift, it is unsurprising that when several indexicals co-occur under Role Shift they shift together. In fact, some examples we already discussed made the desired point. Thus in our ASL sentence with wh-extraction displayed in (6), the two indexicals $I X-1$ and HERE obligatorily received a shifted interpretation. Similarly, we saw in (40b) that under Attitude Role Shift both $I X-1$ and NOW MORNING were obligatorily shifted, and in (42b) that $I X-1$ and TOMORROW were both obligatorily shifted as well. Under Action Role Shift, the generalization is harder to test in our data because examples that involve two indexicals have at least one overt one - and this usually triggers an attitude reinterpretation rather than an action report reading.

In LSF, the data are clear for Attitude Role Shift: in (20) and (21), discussed above, two indexicals are found under Attitude Role Shift, and both must receive a shifted interpretation - which is expected since indexicals that appear singly under Role Shift are obligatorily shifted (as noted above, we have similar data pertaining to the simultaneous shifting of $I X-1$ on the one hand, and NOW, TOMORROW, THE-DAY-BEFORE-YESTERDAY, and (less clearly) YESTERDAY on the other). Here too, testing the same phenomena under Action Role Shift is complex due to the attitude reinterpretation or deviance that overt indexicals often trigger for our consultant. 
Super monsters I

\section{A context-shifting analysis of ASL and LSF role shift}

In the rest of this piece, we will focus on ASL and LSF Attitude and Action Role Shift, leaving aside data from German and Catalan Sign Language. This has the advantage of allowing for a simple formal framework in which context dependency is treated by way of implicit parameters, as in Anand 2006 and Anand \& Nevins 2004. Frameworks that allow for 'Mix Perspectives' must make provisions to allow different indexicals from a given clause to be evaluated with respect to different contexts. One way to achieve this result is to allow some indexicals to covertly move out of the scope of context-shifting operators. An 'in situ' alternative is to have context variables in the object language, and allow different indexicals to carry different context variables, as in Schlenker 2003 (see also Schlenker 2011 for a way to capture on this basis a typology in which some constructions force 'Shift Together' while others allow for 'Mix Perspectives' [based on a suggestion by Ede Zimmermann].)

We believe our implementation might be compatible with some insights expressed by other authors in very different frameworks. In particular, S. K. Liddell \& Metzger 1998 provided an analysis of 'constructed action' within Mental Space theory (see also S. Liddell 1998). At the heart of their analysis is the notion of 'blend' of two mental spaces, one corresponding to the real context, and one to the reported situation. The availability to two distinct contexts can be viewed as a result of this blend of two mental spaces. While Liddell and Metzger do discuss the effect of constructed action on deictic elements (as we do in this part), much of their focus is on iconic elements - whose behavior we will revisit in Part II. Our own analysis is developed within standard model-theoretic semantics because this framework has the advantage of delivering precise predictions about truth conditions and inferences, and also of requiring explicit decisions about the possible points of evaluation of different types of indexicals; we leave a comparison with Liddell and Metzger's framework for future research.

\subsection{Theoretical directions}

Our data from Attitude Role Shift in ASL and LSF have the hallmarks of a standard argument for a context-shifting analysis. We will argue that Action Role Shift also shifts a context parameter, but that the context obtained in this way is not of the 'right type' for most indexicals; more specifically, we will posit that most indexicals come with a presupposition that the context with respect to which they are evaluated is a context of speech or of thought - a condition which is not usually guaranteed to hold in Action Role Shift. 
Now one could argue that Attitude Role Shift involves bona fide context shift while Action Role Shift doesn't. In fact, Zucchi 2004 provides an analysis of some instances of Action Role Shift in Italian Sign Language (= LIS) by positing an operator that does not shift the context, but rather assigns to first person pronouns under Role Shift the value of the shifted perspectival center. This analysis could not account for Attitude Role Shift in ASL and LSF, since in that environment all indexicals - most of which are not variable-like - have a shifted reading. Still, Zucchi's analysis might initially seem appealing to account for Action Role Shift in ASL and LSF: in our data, only the first person agreement marker freely shifts in such circumstances, and Zucchi's operator could target first person pronouns without affecting bona fide indexicals. But this analysis would miss an important fact: in ASL and LSF, Action Role Shift has an effect on all indexicals. Specifically, under (apparent) Action Role Shift ASL indexicals that fail to shift tend to trigger an attitude reinterpretation, while LSF indexicals tend to have the same effect or to just be deviant. A theory that leaves the context parameter untouched by Action Role Shift would fail to account for this effect. By contrast, our context-shifting theory will posit that (i) the context parameter is shifted as a result of Role Shift, but that (ii) it fails to get a value of the appropriate type for most indexicals - hence an attitude reinterpretation or simple deviance when these indexicals are used under (apparent) Action Role Shift.

How can a unified analysis of Attitude and Action Role Shift be developed? The two constructions differ in that the former is intensional while the latter is extensional; schematically, JOHN SAY RS F does not entail that $F$ in fact holds (as $S A Y$ isn't factive), whereas JOHN IX-a RS F does entail that the action corresponding to $F$ was accomplished by John (an 'actuality entailment'). Technically, we will follow standard analyses of context shift (e.g. Schlenker 2003, 2011) in assuming that attitude verbs take as arguments centered propositions, ones obtained by an operation of 'abstraction over contexts'. There are two ways to develop the theory.

- If we start from Action Role Shift, we can take the Role Shift operator to replace one context parameter with another, without triggering any intensional abstraction. If so, intensional abstraction must be triggered by independent means in the case of Attitude Role Shift.

- By contrast, if we start from Attitude Role Shift, we may want the Role Shift operator to deliver a centered proposition, and thus to trigger intensional abstraction 'from the start'; if so, we will have to ensure that in Action Role Shift this centered proposition is fed the appropriate individual and world arguments to obtain in the end the desired actuality entailments. 
Super monsters I

Let us examine both options in greater detail. For simplicity, we adopt a system in which there are world parameters but no time parameters; and we take contexts to be just pairs of the form <agent of the context, world of the context>, as stated in (57).

(57) A context is a pair of an individual and a world, of the form <agent of the context, world of the context $>$.

Option 1. We can take as a starting point the behavior of Action Role Shift, and assume that the Role Shift operator simply replaces the 'old' context parameter with a new one, as in the rule sketched in (58). ${ }^{37}$

(58) If $\mathrm{c}$ is a context, $\mathrm{s}$ an assignment function and w a world parameter, and if $I P$ is a clause, $\llbracket R S_{i} I P \rrbracket^{c, s, w}=\llbracket I P \rrbracket^{<s(i), w>, s, w}$.

When this lexical entry is adopted, we can obtain the desired meaning for Action Role Shift if we posit that an individual abstractor is added to guarantee that the roleshifted clause obtains a predicative type and can thus take an individual argument, as is illustrated in the Logical Form in (59).

\section{IX-a $\lambda$ a $\mathrm{RS}_{\mathrm{a}}\left[1\right.$-WALK-WITH-ENERGY $\left.\varnothing_{1}\right]$}

For Attitude Role Shift, something else is needed to trigger the intensional abstraction by which a centered proposition is obtained as the value of the embedded clause. This can be effected by a special operator (or by the semantics of the attitude verb) - for instance by the operator $O p_{i}$ in (60), which will have the effect of binding the index $i$ of $R S_{i}$ in configurations such as (61).

$$
\llbracket \mathrm{Op} \mathrm{p}_{\mathrm{i}} \mathrm{IP} \rrbracket^{\mathrm{c}, \mathrm{s}, \mathrm{w}}=\lambda \mathrm{x}^{\prime}{ }_{e} \cdot \lambda \mathrm{w}^{\prime}{ }_{s} \cdot \llbracket \mathrm{IP} \rrbracket^{\mathrm{c}, \mathrm{s}\left[\mathrm{i} \rightarrow \mathrm{x}^{\prime}\right], \mathrm{w}^{\prime}}
$$

\section{IX-a SAY Op $\mathrm{RS}_{\mathrm{i}}$ [IX-1 WILL-LEAVE]}

Option 2. An alternative is to treat the Role Shift operator as an intensional construction, one that immediately delivers a centered proposition by way of a 'diagonalization operator' that simultaneously shifts the context and the world parameter, as in (62). Note that the index $i$ plays no semantic role in this analysis, unlike what is the case in Option 1; we keep $i$ in our notation because it is standard in sign language transcriptions to indicate how Role Shift is realized, but on the current semantics it is not interpreted as a variable.

37 Anand \& Nevins 2004 also assumed a modal framework with context parameters (rather than context variables), and they posited an operator that replaces the context parameter with one whose coordinates are obtained from the world parameter (intensional abstraction was assumed to be triggered by composition rules when a clause was embedded under an attitude operator). By contrast, in (58) the 'new' elements of the context parameter are obtained from the Role Shift operator. 


$$
\llbracket \mathrm{RS} \mathrm{S}_{\mathrm{i}} \mathrm{IP} \rrbracket^{\mathrm{c}, \mathrm{s}, \mathrm{w}}=\lambda \mathrm{x}^{\prime}{ }_{e} \lambda \mathrm{w}^{\prime}{ }_{s} \cdot \llbracket \mathrm{IP} \rrbracket^{<\mathrm{x}, \mathrm{w}^{\prime}>, \mathrm{s}, \mathrm{w}^{\prime}}=1
$$

When this option is chosen, the analysis of attitude reports is straightforward, but one must guarantee that in the case of Action Role Shift an individual and a world argument are provided to the role-shifted clause so it can yield a truth value in the end.

For reasons that will become apparent in Part II (Appendix II), we go with Option 2 in the body of this paper, but we develop Option 1 in Appendix III; both options are equally appropriate to handle the data we discuss in this part. ${ }^{38}$

\subsection{A context-shifting analysis: first steps}

We will now sketch an implementation of our analysis within a trivalent model theoretic framework, with the third value called \# (the trivalence is necessary because we wish to analyze some cases of Action Role Shift as triggering a presupposition failure $)^{39}$. To simplify notation, we write as leave' the value of an object-language expression such as LEAVE (we assume that leave' takes its world argument in subscript notation, and its individual argument in functional notation - hence notations such as leave'w(x)). For the rest, we assume a standard type-theoretic intensional logic with individual assignment functions, world and context parameters; and we take contexts to be just pairs of an individual and a world: ${ }^{40}$

38 Two remarks are in order.

(i) As discussed in fn. 51 in Appendix III, Option 1 might have to be constrained to enforce coindexing of $O p_{i}$ and $R S_{i}$ in (61) (an issue brought up by an anonymous reviewer).

(ii) Irrespective of (i), we go for Option 2 because a crucial rule in Part II will make reference to 'maximally iconic' interpretations of role-shifted clauses. This analysis is motivated by strong iconic effects found in Action Role Shift, but also by strong quotational effects seen in Attitude Role Shift. Now to derive the latter it is necessary to state that the role-shifted clause should maximally resemble some features of the thought or speech situation described by the relevant clause. This can be achieved if we have a rule that requires that the form of $R S_{i} I P$ must maximally resemble some aspects of the situation corresponding to the relevant attitude in the world of evaluation $w$. For this reason, it is important that the world of evaluation of $R S_{i}$ $I P$ should be the same as the world of evaluation of the attitude verb. This is unproblematic in Option 2, but not in Option 1: the latter requires that in Attitude Role Shift the construction $R S_{i}$ $I P$ should be further embedded under an intensional operator $O p_{i}$ which simultaneously binds the variable $i$ and shifts the world of evaluation, as is the case in (60).

39 See for instance Heim \& Kratzer 1998 for a textbook treatment of presupposition failure, and Beaver $\&$ Geurts 2014 for a survey of presupposition theory.

40 This yields a broader class of contexts than in standard Kaplanian frameworks, as the contexts may be improper: the author of the context need not be an individual who exists and is speaking in the world of the context; see for instance Schlenker 2011 for discussion 
Super monsters I

(63) a. Let $\mathrm{D}$ be a set of individuals and let $\mathrm{W}$ be a set of possible worlds. The set of contexts is $\mathrm{C}=\mathrm{D} \times \mathrm{W}$, and if $\mathrm{c} \in \mathrm{C}$ with $\mathrm{c}=\langle\mathrm{x}, \mathrm{w}>$, we write the author coordinate of $\mathrm{c}$ as $\mathrm{c}_{\mathrm{a}}(=\mathrm{x})$ and its world coordinate as $\mathrm{c}_{\mathrm{w}}(=\mathrm{w})$.

b. As is standard, the type of individuals is written as e and the type of worlds is written as s.

Within this general framework, the definition of truth is standard, as shown in (64).

(64) Definition of Truth (to be refined in (82))

If a sentence $\mathrm{S}$ is uttered by an individual $\mathrm{x}$ in a world $\mathrm{w}$ and if the assignment function s properly represents the referential intentions of $\mathrm{x}$ in $\mathrm{w}$ with respect to the values of free variables in $S, S$ results in a presupposition failure iff $\llbracket S \rrbracket^{<x, w>, s, w}=\#$, and $S$ is true if and only if $\llbracket S \rrbracket^{<x, w>, s, w}=1$.

To develop Option 2, we define the context-shifting operator in (65):

(65) Semantics of $\overline{I P}$, written as $R S_{i} I P$

Let $\mathrm{c}$ be a context, $\mathrm{s}$ an assignment function and $\mathrm{w}$ a world. Then for any index i and clause $I P, \llbracket \mathrm{RS}_{\mathrm{i}} \mathrm{IP} \rrbracket^{\mathrm{c}, \mathrm{s}, \mathrm{w}}=\lambda \mathrm{x}^{\prime}{ }_{e} \lambda \mathrm{w}^{\prime}{ }_{s \cdot} \cdot \llbracket \mathrm{IP} \rrbracket^{<\mathrm{x}^{\prime}, \mathrm{w}^{\prime}>, \mathrm{s}, \mathrm{w}}$

On this treatment, $R S_{i}$ is in essence a 'diagonalization operator' within a Kaplanian logic of demonstratives ${ }^{41}$ (as noted in our discussion of Option 2 in Section 7.1, the subscript $i$ plays no semantic role in this account; we keep it because it reflects how the Role Shift is realized). It allows us to follow simple analyses developed in the literature to account for shifted indexicals (e.g. Schlenker 2003, 2011). But the application of this context-shifting operator outside of attitude reports is unusual: to our knowledge, all formal discussions of such context shifts (involving the context of evaluation of indexicals like $I$ and here) in the literature involve attitudes of some sort or other. Still, the analysis turns out to be unproblematic once it is assumed that sign language has access to covert world pronominals which can be 'fed' as arguments of the role-shifted clause in descriptions of actions, as we will see shortly.

\subsubsection{Attitude Role Shift}

We start with the case of Attitude Role Shift. Consider (66a), analyzed as in (66b) (since we leave time dependencies out of the present discussion, we treat WILL$L E A V E$ as a single atomic unit).

41 Briefly, a 'diagonalization operator' takes as input a Kaplanian meaning $\mathbf{M}$ and returns as output the set of contexts $\mathrm{c}$ such that $\mathrm{M}$ is true in c relative to the world of $\mathrm{c}$. On the right-hand side of (65), we simultaneously abstract over x' and w', and <x', w'> counts as the 'new' context that replaces c, while w' replace $w$. 

$\mathrm{RS}_{\mathrm{a}}$
a. IX-a SAY IX-1 WILL LEAVE
b. IX-a SAY RS a $_{\mathrm{a}}$ [X-1 WILL-LEAVE]

We start with the standard assumption on the interpretation of first person pronouns in (67), which allows us derive the meaning of the role-shifted clause, as in (68):

(67) Let $\mathrm{c}$ be a context, $\mathrm{s}$ an assignment function and $\mathrm{w}$ a world. Then: $\llbracket \mathrm{IX}-1 \rrbracket^{\mathrm{c}, \mathrm{s}, \mathrm{w}}=\mathrm{c}_{\mathrm{a}}$

(68) Let $\mathrm{c}$ be a context, $\mathrm{s}$ an assignment function and $\mathrm{w}$ a world of evaluation. $\llbracket \mathrm{RS}_{\mathrm{a}}\left[\mathrm{IX}-1\right.$ WILL-LEAVE] $\rrbracket^{\mathrm{c}, \mathrm{s}, \mathrm{w}}$ $=\lambda \mathrm{x}^{\prime}{ }_{e} \lambda \mathrm{w}^{\prime}{ }_{s} \cdot \llbracket \mathrm{IX}-1$ WILL-LEAVE $\|^{<\mathrm{x}^{\prime}, \mathrm{w} '>\mathrm{s}, \mathrm{w}}$

$=\lambda \mathrm{x}^{\prime}{ }_{e} \lambda \mathrm{w}^{\prime}{ }_{s} \cdot \llbracket$ [WILL-LEAVE $\rrbracket^{<\mathrm{x}^{\prime}, \mathrm{w}^{\prime}>, \mathrm{s}, \mathrm{w}^{\prime}}\left(\llbracket \mathrm{IX}-1 \rrbracket^{\left.<\mathrm{x}^{\prime}, \mathrm{w}^{\prime}>, \mathrm{s}, \mathrm{w}^{\prime}\right)}\right.$

$=\lambda \mathrm{x}^{\prime}{ }_{e} \lambda \mathrm{w}^{\prime}{ }_{s} \cdot \mathrm{will}$-leave' ${ }_{\mathrm{w}}{ }^{\prime}\left(\mathrm{x}^{\prime}\right)$

The final truth conditions can be obtained once we avail ourselves of a standard De Se semantics for attitude verbs, as in (69). ${ }^{42}$

a. Let $\mathrm{SAY}_{\mathrm{w}}(\mathrm{x})$ be the set of contexts compatible with what individual says in world $\mathrm{w}$.

For object $\mathrm{p}$ of type $<\mathrm{e},<\mathrm{s}$, t» (where $\mathrm{s}$ is the type of worlds), for any individual $\mathrm{x}$, for any context $\mathrm{c}$, assignment function $\mathrm{s}$ and world $\mathrm{w}$, $\llbracket \operatorname{SAY} \rrbracket^{c, s, w}(p)(x)=\#$ iff for some $c^{\prime} \in \operatorname{SAY}_{\mathrm{w}}(\mathrm{x}), \mathrm{p}\left(\mathrm{c}^{\prime}{ }_{\mathrm{a}}\right)\left(\mathrm{c}^{\prime}{ }_{\mathrm{w}}\right)=\#$. If $\neq \#$, $\llbracket \mathrm{SAY}^{\mathrm{c}, \mathrm{s}, \mathrm{w}}(\mathrm{p})(\mathrm{x})=1$ iff for every $\mathrm{c}^{\prime} \in \mathrm{SAY}_{\mathrm{w}}(\mathrm{x}), \mathrm{p}\left(\mathrm{c}^{\prime}{ }_{\mathrm{a}}\right)\left(\mathrm{c}^{\prime}{ }_{\mathrm{w}}\right)=1$.

b. An analogous rule can be defined for THINK, replacing $S A Y_{w}(x)$ with $\operatorname{THINK}_{w}(x)$.

With these tools in hand, we can give a complete derivation of the truth conditions of (66a), analyzed as in (66b).

$$
\begin{aligned}
& \llbracket 66 b \rrbracket^{c, s, w} \\
& =\llbracket \mathrm{SAY} \rrbracket^{\mathrm{c}, \mathrm{s}, \mathrm{w}}\left(\llbracket \text { RS }_{\mathrm{a}}\left[\mathrm{IX}-1 \text { WILL-LEAVE } \rrbracket^{\mathrm{c}, \mathrm{s}, \mathrm{w}}\right)\left(\llbracket \mathrm{IX}-\mathrm{a} \rrbracket^{\mathrm{c}, \mathrm{s}, \mathrm{w}}\right)\right. \\
& =\llbracket \mathrm{SAY} \rrbracket^{\mathrm{c}, \mathrm{s}, \mathrm{w}}\left(\lambda \mathrm{x}{ }_{e}{ }_{e} \lambda \mathrm{w}{ }_{s} \cdot{ } \cdot \text { will-leave' }{ }_{\mathrm{w}}{ }^{\prime}\left(\mathrm{x}^{\prime}\right)\right)(\mathrm{s}(\mathrm{a})) \\
& =1 \text { iff for every c' } \in \operatorname{SAY}_{\mathrm{w}}(\mathrm{s}(\mathrm{a})) \text {, will-leave' }{ }_{\mathrm{w}}{ }^{\prime}\left(\mathrm{c}_{\mathrm{a}}\right)=1 ;=0 \text { otherwise. }^{43}
\end{aligned}
$$

In other words, we obtain a De Se reading according to which in every context c' compatible with what the agent s(a) says in the world of evaluation w, the agent of c' will leave in the world of c'. This seems appropriate: as we argued in Section 3.4, ASL role-shifted clauses under attitude verbs are indeed read De Se. 
Super monsters I

There has been a subtle debate in spoken language semantics to determine whether in the absence of dedicated De Se constructions (such as control and logophoric pronouns), standard English-style pronouns are only read De Re, or are ambiguously De Re or De Se. The majority opinion seems to be for an ambiguity view (see for instance Schlenker 2011 for a brief survey; key arguments are given in Percus \& Sauerland 2003). We will not attempt to address the empirical side of the question for non-role-shifted clauses in sign language. But on a formal level it is worth noting that De Re and De Se readings without Role Shift can be obtained on the basis of the covert operator $O p_{i}$ (optionally binding an individual variable $i$ ) defined as in (71).

(71) For any clause F, context c, assignment function s and world w, $\left.\llbracket \mathrm{Op}_{\mathrm{i}} \mathrm{F} \rrbracket^{\mathrm{c}, \mathrm{s}, \mathrm{w}}=\lambda \mathrm{x}{ }_{e} \lambda \mathrm{w}{ }_{s} \cdot \llbracket \mathrm{F} \rrbracket^{\mathrm{c}, \mathrm{s}[\mathrm{i} \rightarrow \mathrm{x}]}\right], \mathrm{w}{ }^{\prime}$

To see that the entry in (71) predicts an ambiguity, consider the two Logical Forms in (72).
a. No Role Shift, De Se Reading

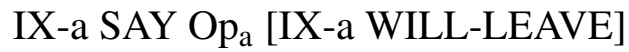
b. No Role Shift, De Re Reading IX-a SAY Op $p_{i}[I X-a$ WILL-LEAVE]

In (72a), the covert operator $O p_{a}$ binds the embedded pronoun $I X-a$, with the result that the latter gets a De Se reading, as shown in (73a). In (73b), the covert operator $O p_{i}$ gets a different index, with the result that it doesn't bind any individual variable in the embedded clause, and that $I X-a$ gets a De Re reading. ${ }^{44}$ (Note that in all cases, the covert operator abstracts over a world parameter).

a. Denotation of the complement of SAY in (72a)

$\llbracket O p_{a}\left[I X-a\right.$ WILL-LEAVE] $\rrbracket^{c, s, w}$

$=\lambda \mathrm{x}^{\prime}{ }_{e} \lambda \mathrm{w}^{\prime}{ }_{s} \cdot \llbracket$ IX -a WILL-LEAVE $\rrbracket^{\mathrm{c}, \mathrm{s}[\mathrm{a} \rightarrow \mathrm{x} \text { '], w' }}$

$=\lambda \mathrm{x}^{\prime}{ }_{e} \lambda \mathrm{w}^{\prime}{ }_{s} .1$ iff $\mathrm{x}$ ' will leave in $\mathrm{w}$ '; 0 otherwise

b. Denotation of the complement of SAY in (72b)

$\llbracket \mathrm{Op}_{\mathrm{i}}[\mathrm{IX}-\mathrm{a}$ WILL-LEAVE] $] \rrbracket^{\mathrm{c}, \mathrm{s}, \mathrm{w}}$

$=\lambda \mathrm{x}{ }_{e} \lambda \mathrm{w}{ }_{s} \cdot \llbracket$ [IX-a WILL-LEAVE $\rrbracket^{\mathrm{c}, \mathrm{s}[\mathrm{i} \rightarrow \mathrm{x} \text { '], w' }}$

$=\lambda \mathrm{x}_{e}{ }_{e} \lambda \mathrm{w}{ }_{s} .1$ iff $\mathrm{s}(\mathrm{a})$ will leave in $\mathrm{w}$ '; 0 otherwise

44 In more sophisticated accounts of attitude reports, De Re readings are obtained by a more complex mechanism of quantification over implicit descriptions; see for instance Schlenker 2011 for a recent overview in connection with the $\mathrm{De} \mathrm{Re} / \mathrm{De}$ Se distinction. 
Philippe Schlenker

\subsubsection{Action Role Shift}

Let us turn to Action Role Shift, illustrated in (74a), which we analyze with a Role Shift operator as in (74b).
$\mathrm{RS}_{\mathrm{a}}$
a. IX-a 1-WALK-WITH-ENERGY(CL-ONE)
b. $\quad \mathrm{w}^{*}$ IX-a $_{\mathrm{RS}}$ [1-WALK-WITH-ENERGY(CL-ONE) $\left.\varnothing_{1}\right]$

In order for (74b) to yield an interpretable sentence, it must include two unpronounced elements, which appear in bold.

- Because our Role Shift operator is intensional, its output is a meaning of type $<e$, $<\mathrm{s}, \mathrm{t}>>$. The argument $I X-a$ can 'fill' the individual slot, but we still need a world argument to obtain a truth value in the end. We assume that the object language contains an unpronounced world term $\mathrm{w}^{*}$, which is intended to denote the world of evaluation and is defined below. ${ }^{45}$

- In line with Schlenker, Lamberton \& Santoro 2013, we take a directional verb that indexes a locus $i$, such as $i$-WALK-WITH-ENERGY, to trigger a presupposition that its argument has the same denotation as $i$. In line with Lillo-Martin 1991 and Lillo-Martin \& Meier 2011, we take directional verbs to license null arguments, hence the presence of the null pronoun $\varnothing_{1}$, which we take to denote the speaker of the context.

Our main semantic assumptions are outlined in (75), and they allow us to provide truth conditions for (74b) in (76).

(75) Preliminary assumptions (to be extended and refined in (84))

For any context $\mathrm{c}$, assignment function $\mathrm{s}$, and world $\mathrm{w}$ :
a. W.
b. $\llbracket \varnothing_{1} \rrbracket^{\mathrm{c}, \mathrm{s}, \mathrm{w}}=\mathrm{c}_{\mathrm{a}}$
c. If $\mathrm{i} \neq 1, \llbracket \mathrm{IX}-\mathrm{i} \rrbracket^{c, s, w}=\mathrm{s}(\mathrm{i})$
d. $\llbracket \mathrm{IXX}-1 \rrbracket^{\mathrm{c}, \mathrm{s}, \mathrm{w}}=\mathrm{c}_{\mathrm{a}}$
e. $\llbracket \mathrm{w}^{*} \rrbracket^{\mathrm{c}, \mathrm{s}, \mathrm{w}}=\mathrm{w}$

$\llbracket 1$-WALK-WITH-ENERGY $\rrbracket^{\mathrm{c}, \mathrm{s}, \mathrm{w}(\mathrm{x})}=\#$ unless $\mathrm{x}=\mathrm{c}_{\mathrm{a}}$. If $\neq \#$, $\llbracket 1$-WALK-WITH-ENERGY $\rrbracket^{c, s, w(x)}=1$ iff walks with energy in

(76) Let $<x, w>$ be the context of utterance, and let $s$ be an assignment function that represents the referential intentions of speaker $\mathrm{x}$ in world $\mathrm{w}$. $\llbracket(74 b) \rrbracket^{<\mathrm{x}, \mathrm{w}>\text {, s, w }}$

45 An alternative would have been to define a syncategorematic rule by which (74)a can be 'fed' the world parameter as a world argument - along the lines of the Montagovian 'cup' operator (Montague 1974). 
Super monsters I

$$
\begin{aligned}
& =\llbracket \mathrm{RS}_{\mathrm{a}}\left[1 \text {-WALK-WITH-ENERGY(CL-ONE) } \varnothing_{1}\right] \rrbracket^{<\mathrm{x}, \mathrm{w}>, \mathrm{s}, \mathrm{w}}\left(\llbracket \text { IX-a } \rrbracket^{<\mathrm{x}, \mathrm{w}>, \mathrm{s}, \mathrm{w}}\right. \\
& =\left[\lambda \mathrm{x}_{e}{ }_{e} \lambda \mathrm{w}^{\prime}{ }_{s} \cdot \llbracket 1-\mathrm{WALK}-\mathrm{WITH}-\mathrm{ENERGY}(\mathrm{CL}-\mathrm{ONE}) \varnothing_{1} \rrbracket<\mathrm{x}^{\prime}, \mathrm{w}^{\prime}>, \mathrm{s}, \mathrm{w}{ }^{\prime}\right](\mathrm{s}(\mathrm{a}))(\mathrm{w}) \\
& =\llbracket 1-\text { WALK-WITH-ENERGY }\left(\text { CL-ONE) } \rrbracket^{<x^{\prime}, w^{\prime}>\text {, s, w' }(s(a))(w)}\right. \\
& =\text { walk-with-energy' }{ }_{\mathrm{w}}(\mathrm{s}(\mathrm{a}))
\end{aligned}
$$

The analysis is straightforward and delivers the intuitively correct truth conditions: despite the context shift, the sentence ends up claiming that the denotation of the subject pronoun $I X-a$ walked away with energy in the world of the context $\mathrm{c}$.

\subsection{Typology of indexicals and refinements of the analysis}

In this section, we develop in two steps an analysis in which the typology of indexicals can be captured. We start with a simple analysis in which all indexicals except the first person agreement marker come with a presuppositional requirement that they should be evaluated with respect to a context of speech or thought. Derived contexts obtained by Action Role Shift usually fail this condition, hence the unacceptability of most indexicals in that environment. Upon closer inspection, however, we will see that this analysis is doesn't quite predict the right inferences, and we will need to posit a more complex presuppositional analysis in which, by virtue of the lexical semantics of attitude verbs, Attitude and Action Role Shift end up manipulating contexts of different semantic types ('primitive' contexts for Attitude Role Shift, 'derived' contexts for Action Role Shift).

\subsubsection{A simple presuppositional analysis}

As we saw, all indexicals we have tested in ASL and LSF are permissible in Attitude Role Shift, but only one of them - the first person agreement marker — was consistently acceptable under Action Role Shift. One could initially try to capture this contrast as a lexical difference between indexicals that are presupposed to be evaluated with respect to a speech/thought context and indexicals that can be evaluated with respect to any context whatsoever; this mirrors the distinction between 'proper contexts', whose author is the agent of a speech act in the world of evaluation, and 'improper contexts', which fail this condition (e.g. Predelli 1998). We provide in (77) the lexical entries this analysis would imply for ASL (note that we do not include the unpronounced world term $\mathrm{w}^{*}$ in this list because the semantics we gave it in (75e) is world- rather than context-dependent, and thus does not qualify as an 'indexical'); first person agreement verbs and the null first person pronoun $\varnothing$ ! impose no particular requirements on the context with respect to which they are evaluated, whereas other indexicals need to be evaluated with respect to a context of speech/thought - if they are evaluated with respect to a different kind of context, 
they trigger a presupposition failure. (As noted before, we do not provide a formal treatment of time dependency in this piece - or for that matter of locations per se; for present purposes, we take locative expressions to denote elements of the set D of individuals).

a. $\quad \llbracket 1$-WALK-WITH-ENERGY $\rrbracket^{\mathrm{c}, \mathrm{s}, \mathrm{w}}(\mathrm{x})=\#$ unless $\mathrm{x}=\mathrm{c}_{\mathrm{a}}$. If $\neq \#$, $\llbracket 1$-WALK-WITH-ENERGY $\rrbracket^{\mathrm{c}, \mathrm{s}, \mathrm{w}}(\mathrm{x})=1$ iff $\mathrm{x}$ walks with energy in $\mathrm{w}$.

b. $\llbracket \varnothing_{1} \rrbracket^{\mathrm{c}, \mathrm{s}, \mathrm{w}}=\mathrm{c}_{\mathrm{a}}$

c. $\quad \llbracket \mathrm{IX}-1 \rrbracket^{\mathrm{c}, \mathrm{s}, \mathrm{w}}=\#$ unless $\mathrm{c}$ is the context of a speech or

d. $\llbracket$ HERE $\rrbracket^{\mathrm{c}, \mathrm{s}, \mathrm{w}}=\#$ unless $\mathrm{c}$ is the context of a speech or thought act. If $\neq \#, \llbracket$ HERE $\rrbracket^{\mathrm{c}, \mathrm{s}, \mathrm{w}}=$ the place of $\mathrm{c}_{\mathrm{a}}$ in $\mathrm{c}_{\mathrm{w}}$

Under some appropriate assumptions, all indexicals will be acceptable under the attitude verbs $S A Y$ and THINK. The necessary assumptions are stated in (78):

(78) Let $\mathrm{SAY}_{\mathrm{w}}(\mathrm{x})$ and let $\mathrm{THINK}_{\mathrm{w}}(\mathrm{x})$ be the set of contexts compatible with what individual says and thinks in world $\mathrm{w}$.

a. For every world $\mathrm{w}$ and individual $\mathrm{x}$, for every context $\mathrm{c}$ in $\mathrm{THINK}_{\mathrm{w}}(\mathrm{x}), \mathrm{c}$ is a context of speech/thought.

b. For every world $w$ and individual $x$, for every context $\mathrm{c}$ in $\mathrm{SAY}_{\mathrm{w}}(\mathrm{x}), \mathrm{c}$ is a context of speech/thought.

(78a) can be justified by a kind of 'awareness' condition: if a context $\mathrm{c}$ is compatible with what $\mathrm{x}$ thinks in $\mathrm{w}$, then $\mathrm{c}$ is itself a context of thought. This would enforce patterns of reasoning of the form: If $x$ thinks that $p, x$ thinks that he is thinking and also that $p$ (though all we need for the theory is the weaker condition: If $x$ thinks that $p$, $x$ thinks that he is thinking or speaking, and also that $p) .{ }^{46}(78 \mathrm{~b})$ can be justified by a kind of 'manifestation' condition: if a context $\mathrm{c}$ is compatible with what $\mathrm{x}$ say in $\mathrm{w}$, then $\mathrm{c}$ is itself a context of speech or thought. This would enforce patterns of reasoning of the form: If $x$ says that $p, x$ says that $x$ is thinking or saying something, and also that p. (78b) is harder to justify on intuitive grounds than (78a).

Under Action Role Shift, the presupposition that the context of evaluation of an indexical such as $I X-1$ is one of speech/thought will usually fail. Thus either $I X-1$ under Action Role Shift will be unacceptable, or one will have to accommodate the assumption that what is reported is a speech or thought act. This result by itself is adequate, since indexicals like $I X-1$ under apparent Action Role Shift trigger an attitude reinterpretation. But on closer inspection, this analysis fails to explain why

46 This pattern follows because if every context in $\operatorname{THINK}_{\mathrm{w}}(\mathrm{x})$ satisfies $p$ (hence: $x$ thinks that $p$ ), it is also the case (by (78a)) that every context in $\operatorname{THINK}_{\mathrm{w}}(\mathrm{x})$ satisfies the condition that $\mathrm{c}_{\mathrm{a}}$ thinks in $\mathrm{c}_{\mathrm{w}}$ - hence: $x$ thinks (De Se) that he is thinking. A similar reasoning applies to (78b). 
Super monsters I

in ASL we don't get an inference that the action was in fact taken (this also holds for some of our LSF data, e.g. (45a)). To be concrete, consider (79a), analyzed for simplicity as (79b) (where EMAIL-rep-FRIENDS is treated as an intransitive verb). In a nutshell, if $a$ denotes John and $w^{*}$ denotes the actual world $\mathrm{c}_{\mathrm{w}}$, we just predict that the presence of $I X-1$ triggers a presupposition that the derived context $<$ John, $\mathrm{c}_{\mathrm{w}}>$ is a context of speech or thought. But the actuality entailments of the extensional context would still follow: when this presupposition is satisfied (by way of accommodation), the sentence should still imply that John did in fact email his friends. By contrast, the intuitive result we obtained from our consultant is that it does not follow that John emailed his friends, only that he said/thought that he did.

$$
\begin{aligned}
& \mathrm{RS}_{\mathrm{a}} \\
& \text { a. IX-a IX-1 1-EMAIL-rep FRIENDS } \\
& \text { b. } \quad \text { w }^{*} \text { IX-a RS } \mathrm{a} \text { [IX-1 1-EMAIL-rep-FRIENDS] } \\
& \text { c. Suppose (a), analyzed as (b), is uttered by an individual } \mathrm{x} \text { in a world w. } \\
& \text { As is standard in trivalent accounts, we assume that a predicate denotation } \\
& \text { yields \# if one of its arguments is itself \#. }{ }^{47} \\
& \llbracket(\mathrm{b}) \rrbracket^{<\mathrm{x}, \mathrm{w}>\mathrm{s}, \mathrm{w}} \\
& =\left[\lambda \mathrm{x}^{\prime}{ }_{e} \lambda \mathrm{w}^{\prime}{ }_{s} \cdot \llbracket \mathrm{IX}-1 \text { 1-EMAIL-rep-FRIENDS } \rrbracket^{<\mathrm{s}^{\prime}, \mathrm{w}^{\prime}>, \mathrm{s}, \mathrm{w}}\right]\left(\llbracket \mathrm{IX}-\mathrm{a} \rrbracket^{<\mathrm{x}, \mathrm{w}>, \mathrm{s}, \mathrm{w}}\right)\left(\llbracket \mathrm{w}^{*} \rrbracket^{<\mathrm{x}, \mathrm{w}>, \mathrm{s}, \mathrm{w}}\right) \\
& =\llbracket I X-1 \text { 1-EMAIL-rep-FRIENDS } \rrbracket^{<\mathrm{s}(\mathrm{a}), \mathrm{w}>\mathrm{s}, \mathrm{w}} \\
& =\llbracket 1 \text {-EMAIL-rep-FRIENDS } \rrbracket^{<\mathrm{s}(\mathrm{a}), \mathrm{w}>\mathrm{s}, \mathrm{w}}\left(\llbracket \mathrm{IX}-1 \rrbracket^{<\mathrm{s}(\mathrm{a}), \mathrm{w}>\mathrm{s}, \mathrm{w}}\right) \\
& \text { Thus, given }(77 \mathrm{c}) \text {, } \\
& \llbracket(b) \rrbracket^{<x, w>s, w}=\# \text { iff }<s(a), w>\text { is not a context of speech or thought }{ }^{48} \text {; } \\
& \text { otherwise, } \llbracket(b) \rrbracket^{<x, w>, s, w}=\text { email-rep-friends' }{ }_{w}(s(a))\left(={ }^{\prime} s(a)\right. \text { is repeat- } \\
& \text { edly emailing friends in world w') }
\end{aligned}
$$

We conclude that this simple presuppositional analysis is not correct.

\subsubsection{A more complex presuppositional analysis}

In a nutshell, the problem is that our initial analysis is that it is too liberal: it allows for accommodation of the assumption that a derived context obtained by Action Role Shift is a context of speech/thought, which in turns predicts that all indexicals should be acceptable in such environments even without the insertion of a covert attitude operator (hence the incorrect actuality entailment we just saw). The solution we will now explore is to make the analysis less liberal by ensuring that derived

47 See for instance Heim \& Kratzer 1998.

48 Note that within a framework without times, $<s(a), w>$ provides all the information about what happens to individual s(a) in world $w$. If we relativized the interpretation function to a time parameter $\mathrm{t}$ in addition to the world parameter $\mathrm{w}$, the condition would become:... < $\mathrm{s}(\mathrm{a}), \mathrm{t}, \mathrm{w}>$ is not a context of speech or thought. 
contexts obtained by Action Role Shift are not of the right semantic type to license the presuppositions of indexicals other than the first person agreement marker. Specifically, we will distinguish formally between two types of contexts:

- Primitive contexts, of the form $<\mathrm{x}^{\mathrm{Q}}, \mathrm{w}^{\mathrm{Q}}>$, where $\mathrm{x}$ is an individual, $\mathrm{w}$ is a world, and the superscript $Q$ indicates that this is a speech or thought context. Formally, we can take $\mathrm{x}^{\mathrm{Q}}$ to be the pair of the individual $\mathrm{x}$ and of a fixed, distinguished object $\mathrm{Q}$, i.e. $\mathrm{x}^{\mathrm{Q}}=<\mathrm{x}, \mathrm{Q}>$; and similarly $\mathrm{w}^{\mathrm{Q}}=<\mathrm{w}, \mathrm{Q}>$. (The intuition is that the objects $\mathrm{x}$ and $\mathrm{w}$ come with a role, namely that of agent and world of a context of speech/thought. $)^{49}$

- Derived contexts, of the form $<\mathrm{x}, \mathrm{w}>$, where $\mathrm{x}$ is an individual and $\mathrm{w}$ is a world. The necessary assumptions are stated in (80).

(80) Contexts

Let $\mathrm{D}$ be the set of individuals, let $\mathrm{W}$ be the set of possible worlds, and let $\mathrm{Q}$ be a distinguished object outside of $\mathrm{D}$ and outside of $\mathrm{W}$.

a. Primitive contexts are members of $\mathrm{C}^{+}=(\mathrm{D} \times\{\mathrm{Q}\}) \times(\mathrm{W} \times\{\mathrm{Q}\})$.

b. Derived contexts are members of $\mathrm{C}=\mathrm{D} \times \mathrm{W}$, where $\mathrm{D}$ is the set of individuals and $\mathrm{W}$ is the set of possible worlds.

c. Agent and world of a context

If c' $\in \mathrm{C}$, the agent c' ${ }_{\mathrm{a}}$ and the world c' ${ }_{\mathrm{w}}$ of c' are defined by: $\mathrm{c}^{\prime}{ }_{\mathrm{a}}=$ the first coordinate of $c^{\prime} ; c^{\prime}{ }_{w}=$ the second coordinate of $c^{\prime}$. (Thus if $c^{\prime}=<x$, $\mathrm{w}>, \mathrm{c}^{\prime}{ }_{\mathrm{a}}=\mathrm{x}$ and $\mathrm{c}^{\prime}{ }_{\mathrm{w}}=\mathrm{w}$.)

If $c^{\prime} \in \mathrm{C}^{+}$, the agent c' ${ }_{\mathrm{a}}$ and the world c' ${ }_{\mathrm{w}}$ of c' are defined by: $\mathrm{c}_{\mathrm{a}}=$ the first coordinate of the first coordinate of $c^{\prime} ; c^{\prime}{ }_{w}=$ the first coordinate of the second coordinate of $\mathrm{c}^{\prime}$. (Thus if $\mathrm{c}^{\prime}=\left\langle\mathrm{x}^{\mathrm{Q}}, \mathrm{w}^{\mathrm{Q}}\right\rangle=\langle<\mathrm{x}, \mathrm{Q}\rangle,\langle\mathrm{w}, \mathrm{Q}\rangle$ $>, \mathrm{c}^{\prime}{ }_{\mathrm{a}}=\mathrm{x}$ and $\mathrm{c}^{\prime}{ }_{\mathrm{w}}=\mathrm{w}$.)

In our type-theoretic system, e refers to the type of individuals and $s$ to the type of worlds. Because we now have 'normal' individuals and worlds and 'contextual' individuals and worlds, these types will have to be redefined:

(81) Types

Let $\mathrm{D}, \mathrm{W}$ and e be as in (80).

a. Standard definition: $\mathrm{e}=\mathrm{D} ; \mathrm{s}=\mathrm{W}$

b. Revised definition: $\mathrm{e}=\mathrm{D} \cup(\mathrm{D} \times\{\mathrm{Q}\}) ; \mathrm{s}=\mathrm{W} \cup(\mathrm{W} \times\{\mathrm{Q}\})$

The definition of truth in (82) guarantees that the initial context of evaluation counts as a 'primitive context'. The semantic stipulations in (83) guarantee that all

49 See Schlenker 2004 for a related use of diacritics in the analysis of indexicals and context shift. 
Super monsters I

the contexts compatible with an individual's claims or thoughts count as primitive contexts.

(82) Definition of Truth (revised)

If a sentence $S$ is uttered by an individual $x$ in a world $w$ and if the assignment function s properly represents the referential intentions of $\mathrm{x}$ in $\mathrm{w}$ with respect to the values of free variables in $\mathrm{S}$,

$S$ results in a presupposition failure iff $\llbracket S \rrbracket^{<x^{Q}, w^{Q}>, s, w}=\#$. If $S$ does not result in a presupposition failure, $S$ is true if and only if $\llbracket S \rrbracket^{<\mathrm{x}^{\mathrm{Q}}, \mathrm{w}^{\mathrm{Q}}>\mathrm{s}, \mathrm{w}}=1$.

(83) Let $\mathrm{x}$ be an individual and let $\mathrm{w}$ be a possible world, and let $\mathrm{SAY}_{\mathrm{w}}(\mathrm{x})$ be the set of contexts compatible with what individual says in world $\mathrm{w}$ and let $\mathrm{THINK}_{\mathrm{W}}(\mathrm{x})$ be the set of contexts compatible with what individual thinks in world $\mathrm{w}$. Then $\mathrm{SAY}_{\mathrm{w}}(\mathrm{x})$ and $\mathrm{THINK}_{\mathrm{w}}(\mathrm{x})$ are sets of primitive contexts, i.e.: $\mathrm{SAY}_{\mathrm{w}}(\mathrm{x}) \in(\mathrm{D} \times\{\mathrm{Q}\}) \times(\mathrm{W} \times\{\mathrm{Q}\})$ $\mathrm{THINK}_{\mathrm{W}}(\mathrm{x}) \in(\mathrm{D} \times\{\mathrm{Q}\}) \times(\mathrm{W} \times\{\mathrm{Q}\})$

Within this modified system, we can state the extended and revised lexical entries in (84) (the definition of the lexical semantics of attitude verbs remains as stated in (69)).

(84) Revised lexical entries

Let $\mathrm{c}$ be a (primitive or derived) context, let $\mathrm{s}$ be an assignment function, let $\mathrm{w}$ be a possible world and let $\mathrm{x}$ be an individual.

a. $\quad$ 1-WALK-WITH-ENERGY $\rrbracket^{\mathrm{c}, \mathrm{s}, \mathrm{w}}(x)=\#$ unless $\mathrm{x}=\mathrm{c}_{\mathrm{a}}$. If $\neq \#$, $\llbracket 1$-WALK-WITH-ENERGY $\rrbracket^{\mathrm{c}, \mathrm{s}, \mathrm{w}}(x)=1$ iff $\mathrm{x}$ walks with energy in $\mathrm{w}$.

b. $\llbracket \varnothing_{1} \rrbracket^{c, s, w}=c_{a}$

c. $\llbracket \mathrm{IX}-1 \rrbracket^{\mathrm{c}, \mathrm{s}, \mathrm{w}}=\#$ unless $\mathrm{c} \in \mathrm{C}^{+}(=(\mathrm{D} \times\{\mathrm{Q}\}) \times(\mathrm{W} \times\{\mathrm{Q}\}))$. If $\neq \#$, $\llbracket \mathrm{IX}-1 \rrbracket^{\mathrm{c}, \mathrm{s}, \mathrm{w}}=\mathrm{c}_{\mathrm{a}}$ (as defined in $\left.(80 \mathrm{c})\right)$

d. We add that with a richer notion of context (involving for instance times in addition to individuals and worlds), we could define a lexical entry for HERE as follows:

$\llbracket$ HERE $\rrbracket^{\mathrm{c}, \mathrm{s}, \mathrm{w}}=\#$ unless $\mathrm{c} \in \mathrm{C}^{+}$. If $\neq \#$, $\llbracket \mathrm{HERE} \rrbracket^{\mathrm{c}, \mathrm{s}, \mathrm{w}}=$ the place corresponding to $\mathrm{c}$ (for instance: the place of the agent of $\mathrm{c}$ at the time of $\mathrm{c}$ in the world of c)

e. $\llbracket \mathrm{w}^{*} \rrbracket^{\mathrm{c}, \mathrm{s}, \mathrm{w}}=\mathrm{w}$

The entries for the expressions in (84a), (84b) and (84e) are identical to what they were before, and they do not impose any special constraints on the types of contexts 
they can depend on. Things are different in (84c) and (84d): $I X-1$ and HERE are taken to yield presupposition failures unless they depend on primitive contexts.

To illustrate, consider a simple case of Attitude Role Shift with an embedded first person pronoun, as in (85a), written in operator notation as in (85b) (we box part of the derivation for future reference).

$$
\begin{aligned}
& \mathrm{RS}_{\mathrm{a}} \\
& \text { a. IX-a SAY [IX-1 WILL-LEAVE] }
\end{aligned}
$$

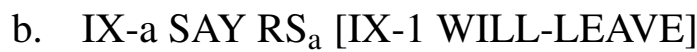

$$
\begin{aligned}
& \text { c. } \llbracket(85 b) \rrbracket^{\mathrm{c}, \mathrm{s}, \mathrm{c}_{\mathrm{w}}}
\end{aligned}
$$

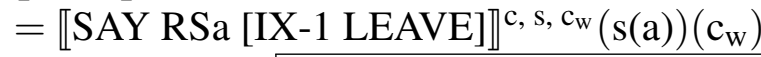

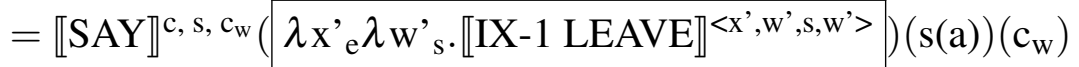

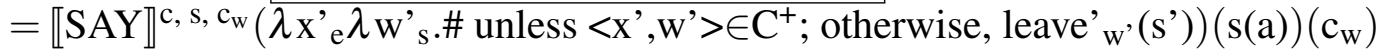

$$
\begin{aligned}
& =\# \text { iff some some } c^{\prime} \in S_{A Y} \mathrm{c}_{\mathrm{w}}(\mathrm{s}(\mathrm{a})) \text {, for some } \mathrm{x}^{\prime}, \mathrm{w}^{\prime} \text { such that } \mathrm{c}^{\prime}=<\mathrm{x}^{\prime}, \mathrm{w}^{\prime}>\text {, } \\
& \mathrm{p}\left(\mathrm{x}^{\prime}\right)\left(\mathrm{w}^{\prime}\right)=\# \text {; otherwise, }=1 \text { iff for every } \mathrm{c}^{\prime} \in \mathrm{SAY}_{\mathrm{c}_{\mathrm{w}}}(\mathrm{s}(\mathrm{a})) \text {, for every } \mathrm{x}^{\prime}, \mathrm{w}^{\prime} \\
& \text { such that } c^{\prime}=<x^{\prime}, w^{\prime}>p\left(x^{\prime}\right)\left(w^{\prime}\right)=1 \text {, with } p=\lambda x^{\prime}{ }_{e} \lambda w^{\prime}{ }_{s} \text {. \# unless }<x^{\prime}, w^{\prime}>\in C^{+} \text {; } \\
& \text { otherwise, leave' } \left.{ }_{w} \text { '( } x^{\prime}\right) \text {. } \\
& \text { Since by construction for every } c^{\prime} \in \operatorname{SAY}_{\mathrm{c}_{\mathrm{w}}}(\mathrm{s}(\mathrm{a})) \text {, if } \mathrm{c}^{\prime}=\left\langle\mathrm{x}^{\prime}, \mathrm{w}^{\prime}\right\rangle,<\mathrm{x}^{\prime} \text {, } \\
& \mathrm{w}^{\prime}>\in \mathrm{C}^{+} \text {, the failure conditions are never met, and thus: } \\
& \llbracket 85 b \rrbracket^{c, s, c_{w}} \neq \# \text {, and } \llbracket 85 b \rrbracket^{c, s, c_{w}}=1 \text { iff for every c' } \in \operatorname{SAY}_{c_{w}}(s(a)) \text {, leave }{ }^{\prime}{ }^{\prime}{ }_{w}\left(c^{\prime} a\right)
\end{aligned}
$$

(It is crucial in this analysis that the revised types e and w, re-defined in (81b), should correspond to the 'large' domains $\mathrm{e}=\mathrm{D} \cup(\mathrm{D} \times\{\mathrm{Q}\})$ and $\mathrm{s}=\mathrm{W} \cup(\mathrm{W} \times\{\mathrm{Q}\})$ respectively, as this is what allows the boxed $\lambda$-abstract in $(85 \mathrm{c})$ to be satisfied, among others, by objects x' and w' that intuitively correspond to the agent and world of a context of speech/thought.)

At this point, our analysis predicts a simple presupposition failure when $I X-1$ or HERE appear under Action Role Shift, as is illustrated in (86). For simplicity, we consider a plain verb (rather than the agreement verb 1-EMAIL-rep, which appeared in our earlier examples with first person agreement).

a. $\mathrm{w}^{*} \mathrm{IX}-\mathrm{a} \mathrm{RS}_{\mathrm{a}}[\mathrm{IX}-1 \mathrm{LEAVE}]$

b. Let $\mathrm{c}$ be a primitive context, with world coordinate $\mathrm{c}_{\mathrm{w}}$, and let $\mathrm{s}$ be an assignment function. As before, we assume that a predicate denotation one of whose arguments is \# yields \# as a value.

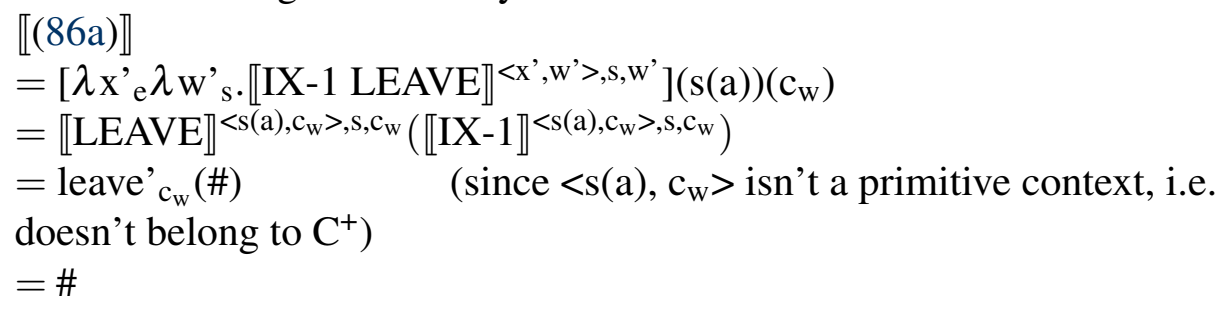


Note that accommodation is not a plausible process to 'save' this sentence: there is no plausible way to accommodate the assumption that the derived context $\left\langle\mathrm{s}(\mathrm{a}), \mathrm{c}_{\mathrm{w}}\right\rangle$ is primitive, since whether a context is primitive or not depends on the operators by which it was introduced, and hence on the linguistic properties of the sentence.

As noted, in ASL sentences with full first person pronouns under Role Shift without an overt attitude operator can be rescued by an attitude reinterpretation. Our account does not capture this fact yet, but the addition in (87) will.

(87) Rescue strategy in ASL

If a sentence results in a presupposition failure because it contains a roleshifted clause $R S_{a}$ which is not embedded under an attitude operator, reinterpret that clause as $S A Y R S_{a}$, where $S A Y$ is a covert version of $S A Y$.

Let us illustrate. As seen in (86), (88a) results in a presupposition failure when evaluated with respect to the parameters $\mathrm{c}, \mathrm{s}, \mathrm{c}_{\mathrm{w}}$. The rescue strategy in (87) can thus be applied, leading to the Logical Form in (88b). Its analysis can proceed as that of (85b), modulo the replacement of the overt verb $S A Y$ with the covert variant $S A Y$.
a. $\mathrm{w}^{*}$ IX-a $\mathrm{RS}_{\mathrm{a}}$ [IX-1 LEAVE]
b. $\mathrm{w}^{*}$ IX-a SAY RS $\mathrm{R}$ [IX-1 LEAVE]

\section{Conclusion}

Two positive conclusions can be drawn from our investigations.

(i) As we saw, Attitude Role Shift could be treated in terms of quotation or context shift. We gave some cautious arguments against an analysis in terms of standard quotation because in ASL wh-extraction is possible out of role-shifted clauses under attitude verbs, but this argument does not exclude an analysis in terms of partial quotation. The main argument against a quotational analysis is that it is insufficiently general, as it fails to account for Action Role Shift. The latter presents its own complexities, since most indexicals cannot appear under it, both in our ASL and in our LSF data. But it would be misguided to propose an analysis without context shift at all, since the fact that Action Role Shift blocks the appearance of most indexicals suggests that it does in fact affect them. Our final analysis captures this observation: most indexicals are required to depend on 'primitive contexts' and yield failures when they are evaluated under a non-primitive one; first person agreement markers are more liberal, and can be evaluated under any context whatsoever. 
(ii) While most of our discussion focused on ASL and LSF, the typology of contextshifting constructions found in sign language illuminates broader questions about context-dependency in language.

- First, we saw that the typological contrast between German and Catalan Sign Language on the one hand, and American and French Sign Language on the other, seems to mirror a typological difference found in spoken languages between languages that allow attitude reports to 'mix perspectives' and ones that require that indexicals 'shift together'. A word of caution should be added, however: in the future, comparative work on all four languages should be conducted with the very same elicitation techniques in order to ensure that the differences we found are not due to methodological rather than substantive differences.

- Second, the existence of Action Role Shift adds something to the typology that has been described for spoken languages, since no uncontroversial cases of context shift without attitude reports have been described in that domain. If no such cases can be found, it will remain to ask why this is.

Several questions are left for future research.

(i) First, we have not attempted to develop a general framework that can handle Role Shift data from American, French, German and Catalan sign languages. As noted, in the latter two languages indexicals that appear in a given roleshifted clause may be interpreted with respect to different contexts, and thus a more expressive framework is needed to handle these data than that used in the present piece. As mentioned above, one way to achieve this result is to allow some indexical expressions to move out of the scope of contextshifting operators (see related considerations in Shklovsky \& Sudo 2014). An alternative is to adopt a more expressive semantics with context variables in the object language, as in Schlenker 2003, 2011; this allows some indexical expressions to be ambiguous 'in situ', i.e. without covert movement.

(ii) Second, our final analysis encoded in the semantics - by way of a distinction between 'primitive' and 'derived' contexts - the requirement that some indexicals should be evaluated with respect to the actual or to a reported speech act, rather than with respect to some other context. In analyses with context variables (or some equivalent based on tuples of variables), the same type of constraints were stated by way of diacritics that appeared in the object language, and were in some cases subject to rules of feature agreement. This was in particular the case in the analyses developed in Schlenker 1999 and von Stechow 2002. In effect, for lack of variables, the present analysis had 
Super monsters I

to put the diacritics in the semantics rather than in the syntax - hence the appearance of semantic objects of the form $<\mathrm{x}, \mathrm{c}>$, and notated as $\mathrm{x}^{\mathrm{c}}$. Here too, future research should develop a more general framework to capture the full typology of indexical dependencies.

(iii) Third, even when concentrating on a single consultant with repeated judgments, we saw that in LSF there was some uncertainty as to the correct generalizations concerning Action Role Shift. And some facts that seemed robust for our consultant are entirely mysterious on the present approach. In particular, while we can explain why overt indexicals lead to deviance or to an attitude reinterpretation under (apparent) Action Role Shift in LSF, the fact that non-indexical nouns sometimes trigger the same kind of reinterpretation (as in (45a)) is mysterious. (The mixed pattern found in (45b) is even more surprising.)

(iv) Fourth, our main generalizations should of course be tested with further consultants. When our ASL and our LSF consultants have stable judgments that converge, it is reasonable to infer that the relevant patterns are rather robust. When they diverge, this may be due to differences between ASL and LSF as such, or to more tenuous differences across consultants - ones that could in principle be replicated internal to ASL or internal to LSF; in such cases, obtaining more data would be particularly important.

Finally, the present analysis has several shortcomings. These are laid out in Part II, where an improved version of the analysis will be developed. Let us mention some of the problems that will be raised:

- Even within ASL, it turns out that further tests of indirect discourse based on NPI licensing yield results that contradict those based on wh-extraction. In this respect, the data do not fit the simple pattern we predict at this point.

- More importantly, ASL and LSF Attitude Role Shift has a strong quotational component which is entirely missed by the present analysis.

- Finally, ASL and LSF Action Role Shift has a strong iconic component which is equally missed by the present analysis.

Part II accounts for these problems within an extension of the present analysis in which Role Shift does involve context shift, but comes with an additional requirement that expressions that appear under Role Shift should be interpreted maximally iconically - which will in particular account for systematic quotational effects under Attitude Role Shift. 
Philippe Schlenker

\section{Appendix I De Se readings and binding}

In order to assess the availability of De Se and non-De Se readings under binding in ASL, we asked our consultant to assess the sentence in (89) under different scenarios.

(89) 10 BOY IX-arc-a EACH-a-rep THINK
a. IX-a SIGN GOOD.
$\mathrm{RS}_{\mathrm{a}}$
b. IX-a SIGN GOOD.
(ASL, 19, 136).

- In Scenario 1, each of the relevant agents has a non-De Se thought about himself. The report in standard indirect discourse is taken to be acceptable and true; the report with a Role Shift and an embedded first person pronoun is judged to be degraded and false. This suggests that the first person pronoun under Role Shift is obligatorily read De Se.

(90) Scenario 1: We showed 10 boys lots of videos of people's hands signing - including videos of each of them signing. None of them recognizes himself, and says [about himself]: 'He signs well'

Assessment of (89a): 6; true

Assessment of (89b): 2; not true

- In Scenario 2, some agents have a De Se thought about themselves, while others have a non-De Se thought about themselves. The report in standard indirect discourse is judged to be acceptable and true, while the report with a first person pronoun under Role Shift is taken to be degraded and false — again an argument that the role-shifted first person pronoun is only read De Se.

(91) Scenario 2: We showed 10 boys lots of videos of people's hands signing - including videos of each of them signing. Some of them recognize themselves, and each of those says: 'I sign well'. Some of them don't recognize themselves, and each [about himself]: 'He signs well'

Assessment of (89a): 6; true [but see the full ratings in Appendix IV]

Assessment of (89b): 2.5; not true

- In Scenario 3, by contrast, each of the relevant agents has a De Se thought about himself. In this case, standard indirect discourse and Role Shift with a first person pronoun are entirely acceptable, and true. The contrast between this case and Scenarios 1 and 2 suggests that the role-shifted first person pronoun is indeed read De Se. 
Super monsters I

(92) Scenario 3: We showed 10 boys lots of videos of people's hands signing — including videos of each of them signing. Each of them recognizes himself, and says: 'I sign well'

Assessment of (89a): 7; true

Assessment of (89b): 7; true

\section{Appendix II Wh-extraction out of Attitude Role Shift and out of quotation in ASL}

In this Appendix, we provide data pertaining to $w h$-extraction out of standard indirect discourse, Attitude Role Shift, and the quotational operator “". It is striking that, for our main ASL consultant, the latter two constructions behave on a par.

We start with cases of extraction out of standard indirect discourse. The $w h$-word can appear in sentence-initial or in sentence-final position, or in both (doubling with the interrogative word in sentence-initial and in situ leads to deviance, however).

(93) Context: The speaker is in NYC; the listener was recently in LA with John. BEFORE IX-a JOHN IN LA,
a. $\quad 6.7$ WHO IX-a SAY
IX-a WILL LIVE WITH THERE
b. 6 IX-a SAY
IX-a WILL LIVE WITH THERE WHO
c. 7 WHO IX-a SAY
IX-a WILL LIVE WITH THERE WHO
d. $\quad 3.7$ WHO IX-a SAY
IX-a WILL LIVE WITH WHO THERE

'While John was in L.A., who did he say he would live with there?'

(ASL, 14, 93)

The very same patterns of acceptability are found under Attitude Role Shift, which suggests that in ASL the latter allows for wh-extraction (unlike what we saw in our LSF data, e.g. (45a)).

(94) Context: The speaker is in NYC; the listener was recently in LA with John.

BEFORE IX-a JOHN IN LA,
a. $\quad 5.7$ WHO IX-a SAY
$\mathrm{RS}_{\mathrm{a}}$
b. $\quad 6.3$ IX-a SAY
IX-a WILL LIVE WITH HERE?
$\mathrm{RS}_{\mathrm{a}}$
IX-a WILL LIVE WITH HERE WHO?
c. $\quad$ 6.7 WHO IX-a SAY
$\mathrm{RS}_{\mathrm{a}}$
IX-a WILL LIVE WITH HERE WHO?
d. $\quad 2.7$ WHO IX-a SAY
IX-a WILL LIVE WITH WHO HERE?

'While John was in L.A., who did he say he would live with there?'

(ASL, 14, 91) 
Finally, the same patterns are also found without (visible) Role Shift but with the use of the quotational operator " ". Thus we must conclude that either (i) " " is not really a quotation operator, but rather a variety of Role Shift; or that (ii) it is genuinely a variety of quotation - in which case we must conclude that quotation marks do not block wh-extraction in ASL.

(95) Context: The speaker is in NYC; the listener was recently in LA with John. BEFORE IX-a JOHN IN LA,
a. $\quad 4.7$ WHO IX-a SAY
“" IX-a WILL LIVE WITH HERE?
b. $\quad$ 6.7 IX-a SAY
“" IX-a WILL LIVE WITH HERE WHO?
c. 6 WHO IX-a SAY
“" IX-a WILL LIVE WITH HERE WHO? ${ }^{50}$
d. 3 WHO IX-a SAY
“" IX-a WILL LIVE WITH WHO HERE?

Approximate translation: 'While John was in L.A., who did he say he would live with there?'

(ASL, 14, 89)

\section{Appendix III An extensional Role Shift operator}

In this Appendix, we define a Role Shift operator that shifts the context parameter without simultaneously abstracting over some parameters. As before, we disregard time dependency, and relativize truth to a context $\mathrm{c}$, an assignment function $\mathrm{s}$ and a world of evaluation w. The semantics of the Role Shift operator is defined in (96). We assume that it affects the value of the entire $I P$ constituent which is its sister, and for simplicity we write $R S_{i}$ before the constituent it applies to rather than above it. (In principle, the two notations could encode different things; our present notation suggests that $R S_{i}$ applies to an entire constituent, whereas the standard notation would make it possible to indicate that the domain of $R S_{i}$ applies to a string that need not be a constituent.) As in the main text, we assimilate contexts to pairs of the form <agent of the context, world of the context $>$. For simplicity, we provide the analysis within the framework we assumed in Section 7.2, and hence without the refinements that involved diacritics, as in Section 7.3.

The extensional Role Shift operator is defined in (96):

50 Jon Lamberton (p.c.) note that in b. and c. alike $W H O$ is preceded by a pause, but is understood to fall within the quotation in $\mathrm{b}$. and after the quotation in $\mathrm{c}$. 
Super monsters I

(96) Semantics of $\overline{I P}$, written as $R S_{i} I P$

Let $\mathrm{c}$ be a context, $\mathrm{s}$ an assignment function and $\mathrm{w}$ a world. Then for any index i and clause $I P$, $\llbracket \mathrm{RS}_{i} \mathrm{IP} \rrbracket^{\mathrm{c}, \mathrm{s}, \mathrm{w}}=1$ iff $\llbracket \mathrm{IP} \rrbracket^{<\mathrm{s}(\mathrm{i}), \mathrm{w}>, \mathrm{s}, \mathrm{w}}=1$

The effect of the operator $R S_{i}$ is quite simple: it shifts the context parameter from c to a new context c' obtained by putting together the world of evaluation $\mathrm{w}$ and the individual s(i) whose perspective is adopted. Note that nothing in this rule guarantees that the new context $<s(i), w>$ is a context of speech or of thought.

\section{III.1 Action Role Shift}

Let us see how this rule can account for the case of Action Role Shift in (97a), already discussed above. We start with the smaller constituent in (97b), written in operator notation as in (97b'):
$\mathrm{RS}_{\mathrm{a}}$
a. IX-a 1-WALK-WITH-ENERGY(CL-ONE)
$\mathrm{RS}_{\mathrm{a}}$
b. 1-WALK-WITH-ENERGY(CL-ONE)
b'. RS $_{\mathrm{a}}$ 1-WALK-WITH-ENERGY(CL-ONE)

To obtain truth conditions, we first need to make some assumptions about the interpretation of directional verbs. In line with Schlenker, Lamberton \& Santoro 2013, we take a directional verb that indexes a locus $i$, such as $i$-WALK-WITHENERGY, to trigger a presupposition that its argument has the same denotation as $i$. In line with Lillo-Martin 1991 and Lillo-Martin \& Meier 2011, we take directional verbs to license null arguments. For simplicity, we restrict attention to a first person version of 1 -WALK-WITH-ENERGY, which we take to license a null argument $\varnothing_{1}$, with the semantic assumptions in (75), copied in (98):

(98) Assumptions (to be refined)

For any context c, assignment function s, and world w:
a. $\quad \llbracket 1$-WALK-WITH-ENERGY $\rrbracket^{\mathrm{c}, \mathrm{s}, \mathrm{w}}(x)=\#$ unless $\mathrm{x}=\mathrm{c}_{\mathrm{a}}$. If $\neq \#, \llbracket 1$-WALK-WITH-ENERGY $\rrbracket^{\mathrm{c}, \mathrm{s}, \mathrm{w}}(x)=1$ iff walk-with-energy' ${ }_{\mathrm{w}}(\mathrm{x})$.
b. $\llbracket \varnothing_{1} \rrbracket^{\mathrm{c}, \mathrm{s}, \mathrm{w}}=\mathrm{c}_{\mathrm{a}}$
c. If $\mathrm{i} \neq 1, \llbracket \mathrm{IX}-\mathrm{i} \rrbracket^{c, s, w}=\mathrm{s}(\mathrm{i})$
d. $\llbracket \mathrm{IX}-1 \rrbracket^{\mathrm{c}, \mathrm{s}, \mathrm{w}}=\mathrm{c}_{\mathrm{a}}$
e. $\llbracket \mathrm{w}^{*} \rrbracket^{\mathrm{c}, \mathrm{s}, \mathrm{w}}=\mathrm{w}$

In this way, we obtain for (97b') the meaning in (99): 
(99) Meaning of (97b')

$\llbracket \mathrm{RS}_{\mathrm{a}}\left[1-\mathrm{WALK}-\mathrm{WITH}-\mathrm{ENERGY} \varnothing_{1}\right] \rrbracket^{\mathrm{c}, \mathrm{s}, \mathrm{w}}$

$=\llbracket 1-$ WALK-WITH-ENERGY $\varnothing_{1} \rrbracket^{<\mathrm{s}(\mathrm{a}), \mathrm{w}>\mathrm{s}, \mathrm{w}}$,

$=\llbracket 1$-WALK-WITH-ENERGY $\rrbracket^{<\mathrm{s}(\mathrm{a}), \mathrm{w}>, \mathrm{s}, \mathrm{w}}\left(\llbracket \varnothing_{1} \rrbracket^{<\mathrm{s}(\mathrm{a}), \mathrm{w}>, \mathrm{s}, \mathrm{w}}\right)$,

$=\llbracket 1$-WALK-WITH-ENERGY $\rrbracket^{<\mathrm{s}(\mathrm{a}), \mathrm{w}>\mathrm{s}, \mathrm{w}}(\mathrm{s}(\mathrm{a}))$,

$=$ walk-with-energy' ${ }_{\mathrm{w}}(\mathrm{s}(\mathrm{a}))$

We can easily account for the 'real' sentence in (97a) by assuming that the initial pronoun $I X$ - $a$ triggered $\lambda$-abstraction, as in the representation in (100b), where we have used the operator notation, and we have included the null argument licensed by the directional verb. (Note that we assume that the same locus can have free and bound uses, which is probably needed on independent grounds when one analyzes bound readings of various sentences with ellipsis and only-constructions; see for instance Schlenker 2014.)
a. IX-a
$\mathrm{RS}_{\mathrm{a}}$
b. IX-a $\lambda \mathrm{a}$
1-WALK-WITH-ENERGY(CL-ONE)
$\mathrm{RS}_{\mathrm{a}}\left[1-\mathrm{WALK}-\mathrm{WITH}-\mathrm{ENERGY} \varnothing_{1}\right]$

The derivation of the final truth conditions is straightforward, as shown in (101):

$$
\begin{aligned}
& \llbracket\left(97 \mathrm{~b}^{\prime}\right) \rrbracket^{\mathrm{c}, \mathrm{s}, \mathrm{w}}=\llbracket \lambda \mathrm{a} \mathrm{RS}_{\mathrm{a}}\left[1-\text { WALK-WITH-ENERGY } \varnothing_{1}\right] \rrbracket^{\mathrm{c}, \mathrm{s}, \mathrm{w}}\left(\llbracket \mathrm{IX}-\mathrm{a} \rrbracket^{\mathrm{c}, \mathrm{s}, \mathrm{w}}\right) \\
& =\left[\lambda x_{e} \llbracket \mathrm{RS}_{\mathrm{a}}\left[1-\text { WALK-WITH-ENERGY } \varnothing_{1}\right] \rrbracket^{\mathrm{c}, \mathrm{s}[\mathrm{a} \rightarrow \mathrm{a}], \mathrm{w}}\right](\mathrm{s}(\mathrm{a})) \\
& =\left[\lambda x_{e} \llbracket 1-\text { WALK-WITH-ENERGY } \varnothing_{1} \rrbracket^{<\mathrm{s}(\mathrm{a}), \mathrm{w}>\mathrm{s}[\mathrm{a} \rightarrow \mathrm{a}], \mathrm{w}}\right](\mathrm{s}(\mathrm{a})) \\
& =\left[\lambda x_{e} \cdot \text { walk-with-energy'}{ }_{\mathrm{w}}(\mathrm{x})\right](\mathrm{s}(\mathrm{a})) \\
& =\text { walk-with-energy'}{ }_{\mathrm{w}}(\mathrm{s}(\mathrm{a}))
\end{aligned}
$$

\section{III.2 Attitude Role Shift}

Let us now consider the case of Attitude Role Shift. We will posit that the very same operation is at work as in Action Role Shift, but that in addition an operator $O p$ associated with a covert complementizer has the effect of abstracting over an individual argument and a world parameter, as in (102). (Alternatively, we could have assumed that a syncategorematic rule of intensional abstraction, rather than the complementizer itself, is responsible for this result.)

(102) For any clause $F$, context c, assignment function s and world w, $\left.\llbracket \mathrm{Op} \mathrm{p}_{\mathrm{i}} \mathrm{F} \rrbracket^{\mathrm{c}, \mathrm{s}, \mathrm{w}}=\lambda x^{\prime}{ }_{e} \lambda w^{\prime}{ }_{s} \cdot \llbracket \mathrm{F} \rrbracket^{\mathrm{c}, \mathrm{s}[\mathrm{i} \rightarrow \mathrm{x}]}\right], \mathrm{w}^{\prime}$

We can immediately apply this lexical entry to the case of Attitude Role Shift in (103), which has the Role Shift operator $R S_{a}$, whose individual argument is bound by the covert operator $O p_{a}$. Since we leave time dependencies out of the present discussion, we treat WILL-LEAVE as a single atomic unit. 
Super monsters I
a. IX-a SAY IX-1 WILL LEAVE
b. IX-a SAY Op $\mathrm{RS}_{\mathrm{a}}$ [IX-1 WILL-LEAVE]

We start by computing the meaning of the role-shifted clause without the covert operator $O p_{a}$; the result is given in (104), which is obtained in the same way as (98):

$$
\begin{aligned}
& \llbracket \mathrm{RS}_{\mathrm{a}}[\mathrm{IX}-1 \text { WILL-LEAVE }] \rrbracket^{\mathrm{c}, \mathrm{s}, \mathrm{w}}=\llbracket \mathrm{IX}-1 \text { WILL-LEAVE } \rrbracket^{<\mathrm{s}(\mathrm{a}), \mathrm{w}>, \mathrm{s}, \mathrm{w}}(\mathrm{s}(\mathrm{a})) \\
& =\text { will-leave' }{ }_{\mathrm{w}}(\mathrm{s}(\mathrm{a})) .
\end{aligned}
$$

Applying the rule in (102), we obtain the value of the sister of $S A Y$ :

$$
\begin{aligned}
& \llbracket \mathrm{Op}_{\mathrm{a}} \mathrm{RS}_{\mathrm{a}} \text { [IX-1 WILL-LEAVE] } \rrbracket^{\mathrm{c}, \mathrm{s}, \mathrm{w}} \\
& =\lambda x_{e}{ }_{e} \lambda w^{\prime}{ }_{s} \cdot \llbracket \mathrm{RS}_{\mathrm{a}}\left[\mathrm{IX}-1 \text { WILL-LEAVE] } \rrbracket^{\mathrm{c}, \mathrm{s}\left[\mathrm{a} \rightarrow \mathrm{x}^{\prime}\right], \mathrm{w}^{\prime}}\right. \\
& =\lambda x^{\prime}{ }_{e} \lambda w^{\prime}{ }_{s} \cdot \llbracket\left[\mathrm{IX}-1 \text { WILL-LEAVE } \rrbracket^{<\mathrm{s}(\mathrm{a}), \mathrm{w}^{\prime}>, \mathrm{s}\left[\mathrm{a} \rightarrow \mathrm{x}^{\prime}\right], \mathrm{w}^{\prime}}\right.
\end{aligned}
$$

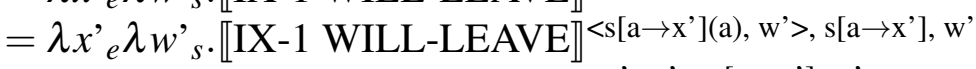

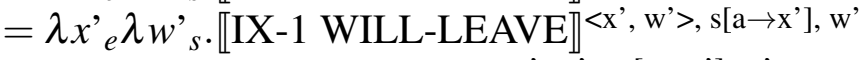

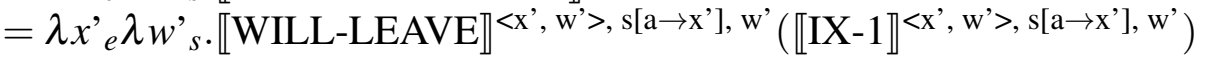

$$
\begin{aligned}
& =\lambda x^{\prime}{ }_{e} \lambda w^{\prime}{ }_{s} \cdot \text { will-leave' }{ }_{\mathrm{w}}{ }^{\prime}\left(\mathrm{x}{ }^{\prime}\right)
\end{aligned}
$$

The denotation defined in (105) is a centered proposition, hence isomorphic to a set of contexts - which is precisely the right kind of object to 'feed' to an attitude verb in order to obtain a De Se reading. The final truth conditions can be obtained once we have availed ourselves of a standard De Se semantics for attitude verbs, as in (69a). This makes it possible to derive the truth conditions of (103a), analyzed as (103b):

$$
\begin{aligned}
& \llbracket(103 b) \rrbracket^{c, s, w} \\
& =\llbracket \text { SAY } \rrbracket^{c, s, w}\left(\llbracket \mathrm{Op}_{\mathrm{a}} \mathrm{RS}_{\mathrm{a}} \text { [IX-1 WILL-LEAVE } \rrbracket^{\mathrm{c}, \mathrm{s}, \mathrm{w}}\right)\left(\llbracket I X-\mathrm{I}-\rrbracket^{\mathrm{c}, \mathrm{s}, \mathrm{w}}\right) \\
& =\llbracket \mathrm{SAY} \rrbracket^{\mathrm{c}, \mathrm{s}, \mathrm{w}}\left(\lambda x^{\prime}{ }_{e} \lambda{ } w^{\prime}{ }_{s} \cdot \text { will-leave' }{ }^{\prime}{ }^{\prime}\left(\mathrm{x}^{\prime}\right)\right)(\mathrm{s}(\mathrm{a})) \\
& =1 \text { iff for every } \mathrm{c}^{\prime} \in \operatorname{SAY}_{\mathrm{w}}(\mathrm{s}(\mathrm{a})) \text {, will-leave }{ }^{\prime}{ }^{\prime}{ }_{\mathrm{w}}\left(\mathrm{c}^{\prime}{ }_{\mathrm{a}}\right)=1 ;=0 \text { otherwise. }
\end{aligned}
$$

In other words, we obtain a De Se reading according to which in every context c' compatible with what the agent s(a) says in the world of evaluation $w$, the agent of c' will leave in the world of c'. This seems appropriate: as we argued in the main text and in Appendix I, in ASL role-shifted clauses under attitude verbs are indeed read De Se.

We also note that the mechanisms we have put in place can in principle predict an ambiguity between a De Se and a De Re reading, as illustrated in (107). 
Philippe Schlenker

(107) a. No Role Shift, De Se Reading

IX-a SAY Op ${ }_{a}$ [IX-a WILL-LEAVE]

b. No Role Shift, De Re Reading

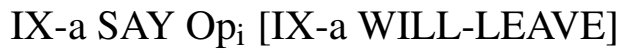

In (107a), the covert operator $O p_{a}$ binds the embedded pronoun $I X-a$, with the result that the latter gets a De Se reading, as shown in (108a). In (107b), the covert operator $O p_{a}$ gets a different index, with the result that it doesn't bind any individual variable in the embedded clause, and that $I X-a$ gets a De Re reading, as shown in (108b). (In all cases, the covert operator abstracts over a world parameter, as we noted above).

(108) a. Denotation of the complement of $S A Y$ in (107a)

$\llbracket O p_{a}\left[I X-a\right.$ WILL-LEAVE] $\rrbracket^{\mathrm{c}, \mathrm{s}, \mathrm{w}}$

$=\lambda x^{\prime}{ }_{e} \lambda w^{\prime}{ }_{s} \cdot \llbracket$ IX-a WILL-LEAVE $\left.\rrbracket^{\mathrm{c}, \mathrm{s}[\mathrm{a} \rightarrow \mathrm{x}}\right] \mathrm{w}$,

$=\lambda x^{\prime}{ }_{e} \lambda w^{\prime}{ }_{s}$. will-leave' ${ }_{\mathrm{w}}{ }^{\prime}\left(\mathrm{x}{ }^{\prime}\right)$

b. Denotation of the complement of $S A Y$ in (107b)

$\llbracket \mathrm{Op}_{\mathrm{i}}\left[\mathrm{IX}-\mathrm{a}\right.$ WILL-LEAVE] $\rrbracket^{\mathrm{c}, \mathrm{s}, \mathrm{w}}$

$=\lambda x^{\prime}{ }_{e} \lambda w^{\prime}{ }_{s \cdot} \cdot \llbracket$ IX-a WILL-LEAVE $\rrbracket^{\mathrm{c}, \mathrm{s}[\mathrm{i} \rightarrow \mathrm{x} \text { '], w' }}$

$=\lambda x^{\prime}{ }_{e} \lambda w^{\prime}{ }_{s} \cdot$ will-leave' ${ }^{\prime}{ }^{\prime}(\mathrm{s}(\mathrm{a}))$

Finally, the typology of indexicals under Role Shift could be obtained in the same way as in the main text: some indexicals come with a presupposition that they are dependent on a speech or thought context, whereas others can depend on any context whatsoever; or in the diacritic-based analysis we ended up, some indexicals must depend on a primitive context, whereas others can also depend on derived contexts. ${ }^{51}$

\section{References}

Anand, Pranav. 2006. De de se. University of California, Santa Cruz dissertation.

51 An anonymous referee asks whether further constraints wouldn't be needed in order to enforce coindexation between $O p_{a}$ and $R S_{a}$ in (103b). Without such constraints, we could generate Logical Forms such as (i), with $\mathrm{i} \neq \mathrm{a}$ :

(i) IX-a SAY Op $\mathrm{RS}_{\mathrm{a}}$ [IX-1 WILL-LEAVE]

While we leave this issue for future research, we note that it involves two questions. First, what are the constructions that are in fact found in sign language? (i) would in effect predict an instance of Action Role Shift within the immediate scope of standard indirect discourse - and maybe such structures can be found. Second, what are the truth conditions predicted for LFs such as (i)? With the lexical choices we made, $I X-1$ is in the scope of Action Role Shift and would presumably be ruled out - although this depends on how one extends to the present analysis the type-based system of (81)-(83). 
Super monsters I

Anand, Pranav \& Andrew Nevins. 2004. Shifty operators in changing contexts. In SALT XIV, 20-37. Ithaca, NY.

Beaver, David \& Bart Geurts. 2014. Presupposition. In Edward N. Zalta (ed.), The Stanford encyclopedia of philosophy. http://plato.stanford.edu/archives/win2014/ entries/presupposition/.

Caponigro, Ivano \& Kathryn Davidson. 2011. Ask, and tell as well: Question-answer clauses in American Sign Language. Natural Language Semantics 19. 323-371.

Heim, Irene \& Angelika Kratzer. 1998. Semantics in generative grammar. Blackwell. Herrmann, Annika \& Markus Steinbach. 2007. Wenn 'ich' nicht ich ist. Zitieren in gebärdensprachen. In Elke Brendel, Jörg Meibauer \& Markus Steinbach (eds.), Zitat und bedeutung. 153-179. Hamburg: Buske.

Herrmann, Annika \& Markus Steinbach. 2012. Quotation in sign languages - a visible context shift. In I. van Alphen \& I. Buchstaller (eds.), Quotatives: Crosslinguistic and cross disciplinary perspectives.

Liddell, Scott. 1998. Grounded blends, gestures, and conceptual shifts. Cognitive Linguistics 9(3). 283-314.

Liddell, Scott K. \& Melanie Metzger. 1998. Gesture in sign language discourse. Journal of Pragmatics 30. 657-697.

Lillo-Martin, Diane. 1991. Universal grammar and American Sign Language (Studies in Theoretical Psycholinguistis). Springer Netherlands. http://dx.doi.org/10. 1007/978-94-011-3468-2.

Lillo-Martin, Diane. 1995. The point of view predicate in American Sign Language. In Karen Emmorey \& Judy Reilly (eds.), Language, gesture, and space, 155-170. Hillsdale, NJ: Lawrence Erlbaum Associates.

Lillo-Martin, Diane \& Richard Meier. 2011. On the linguistic status of 'agreement' in sign languages. Theoretical Linguistics 37(3/4). 95-141.

Lillo-Martin, Diane \& Ronice M. de Quadros. 2011. Acquisition of the syntaxdiscourse interface: The expression of point of view. Lingua.

Maier, Emar. to appear. Mixed quotation: The grammar of apparently transparent opacity. Semantics \& Pragmatics.

Maier, Emar. 2014. Mixed quotation. Manuscript, University of Groningen.

Metzger, Melanie. 1995. Constructed dialogue and constructed action in American Sign Language. In C. Lucas (ed.), Sociolinguistics in Deaf communities, 255271. Washington, DC: Gallaudet University Press.

Montague, Richard. 1974. Formal philosophy: Selected papers of Richard Montague. Richmond Thomason (ed.). Yale University Press.

Morgan, J. 1970. On the criterion of identity for noun phrase deletion. In Papers from the 6th regional meeting of the CLS, 380-389. Chicago: The Chicago Linguistics Society. 
Padden, Carol A. 1986. Verbs and role-shifting in American Sign Language. In Carol A. Padden (ed.), Proceedings of the fourth national symposium on sign language research and teaching. Silver Spring, MD: National Association of the Deaf.

Pearson, Hazel. 2012. The sense of self: Topics in the semantics of de se expressions. Harvard dissertation.

Percus, Orin \& Uli Sauerland. 2003. On the LFs of attitude reports. In Proceedings of Sinn und Bedeutung, vol. 7, 228-242.

Predelli, Stefano. 1998. Utterance, interpretation and the logic of indexicals. Mind and Language 13. 400-414.

Quer, Josep. to appear. Attitude ascriptions in sign languages and role shift. In L. C. Geer (ed.), Proceedings of the 13th Texas Linguistics Society (TLS) meeting.

Quer, Josep. 2005. Context shift and indexical variables in sign languages. In SALT $X V$. Ithaka, NY: CLC Publications.

Quer, Josep. 2011. Reporting and quoting in signed discourse. In Elke Brendel, Jorg Meibauer \& Markus Steinberg (eds.), Understanding quotation, 277-302. Berlin: Mouton de Gruyter.

Rice, Keren D. 1986. Some remarks on direct and indirect speech in Slave (Nothern Athapaskan). In Florian Coulmas (ed.), Direct and indirect speech, 47-76. Berlin: Mouton.

Sandler, Wendy \& Diane Lillo-Martin. 2006. Sign language and linguistic universals. Cambridge University Press.

Schlenker, Philippe. 1999. Propositional attitudes and indexicality: A cross-categorial approach. MIT dissertation.

Schlenker, Philippe. 2003. A plea for monsters. Linguistics \& Philosophy 26. 29120.

Schlenker, Philippe. 2004. Person and binding: A partial survey. Italian Journal of Linguistica / Rivista di Linguistica 16(1). [special issue on Person, ed. K. Safir and V. Biancch], 155-218.

Schlenker, Philippe. 2011. Indexicality and de se reports. In von Heusinger, Maienborn \& Portner (eds.), Semantics, vol. 2. Mouton de Gruyer.

Schlenker, Philippe. 2014. Iconic features. Natural Language Semantics 22(4). 299 356.

Schlenker, Philippe, Jon Lamberton \& Mirko Santoro. 2013. Iconic variables. Linguistics and Philosophy 36(2). 91-149. http://dx.doi.org/10.1007/s10988-0139129-1.

Shklovsky, Kirill \& Yasutada Sudo. 2014. The syntax of monsters. Linguistic Inquiry 45(3). 381-402.

von Stechow, Arnim. 2002. Feature deletion under semantic binding: Tense, person, and mood under verbal quantifiers. In NELS 33. 
Super monsters I

Zucchi, Sandro. 2004. Monsters in the visual mode? Unpublished Manuscript, Universita degli Studi di Milano.

Philippe Schlenker

Institut Jean-Nicod, CNRS

UMR 8129, ENS/EHESS

PSL Research University

F-75005 Paris, France

philippe.schlenker@gmail.com 